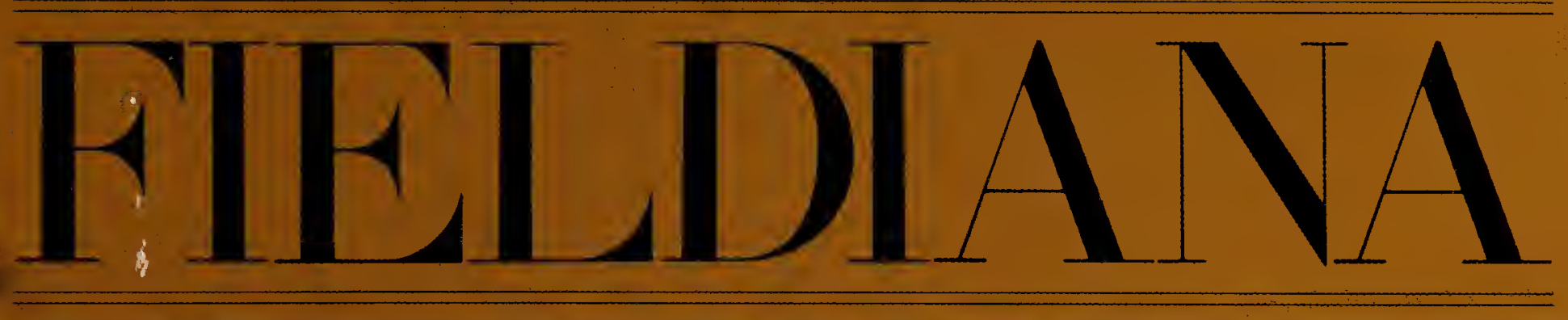

Zoology

NEW SERIES, NO. 116

Contributions to the Natural History of Seven Species of Bornean Frogs

Robert F. Inger

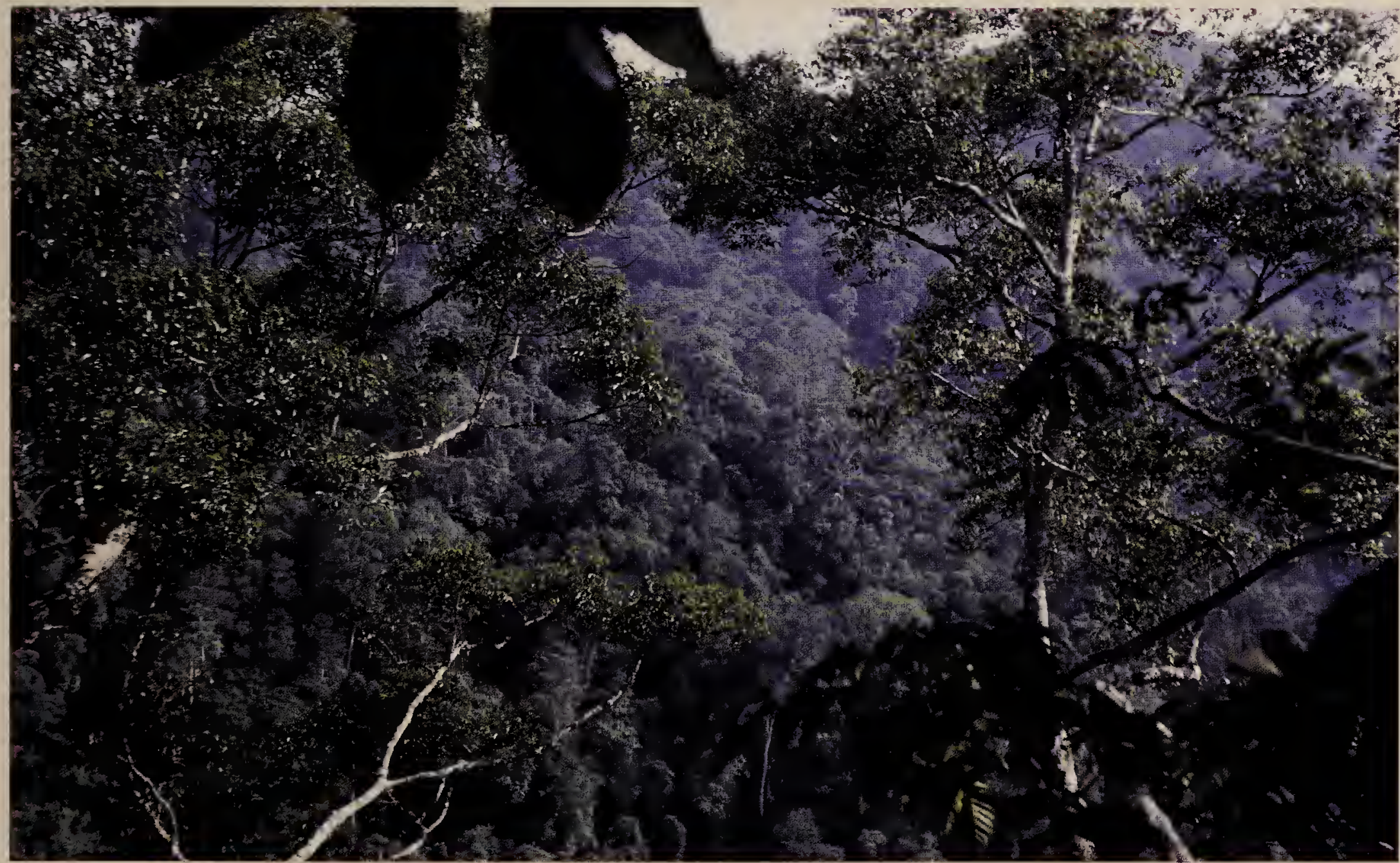

October 8, 2009

Publication 1552

PUBLISHED BY FIELD MUSEUM OF NATURAL HISTORY 


\section{FIELIDINA}

\section{Mission}

Fieldiana is a peer-reviewed monographic series published by the Field Museum of Natural History. Fieldiana focuses on mid-length monographs and scientific papers pertaining to collections and research at The Field Museum. The four series pertain to subject matter in the fields of Anthropology, Botany, Geology, and Zoology.

\section{Eligibility}

Field Museum curators, research associates, and full-time scientific professional staff may submit papers for consideration. Edited volumes pertaining to Field Museum collections may also be submitted for consideration under a subsidy arrangement. The submission and peer review of these chaptered volumes should be arranged well in advance with the managing scientific editor and the appropriate associate editor.

\section{Submission Procedures}

Submission procedures are detailed in a separate document called "SUBMISSIONS PROCEDURES"

available on the Fieldiana web site: (http://www.fieldmuseum.org/research_collections/fieldiana/) under the Author's page. All manuscripts should be submitted to the managing scientific editor.

\section{Editorial Contributors:}

\section{Managing Scientific Editor}

Harold K. Voris (hvoris@fieldmuseum.org)

\section{Editorial Assistant}

Chris Jones (cjones2@fieldmuseum.org)

\section{Anthropology}

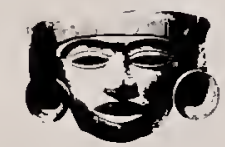

\section{Co-Associate Editors}

Jonathan Haas (jhaas@fieldmuseum.org)

Gary Feinman (gfeinman@fieldmuseum.org)

Geology

\section{Associate Editor}

Olivier Rieppel (orieppel@fieldmuseum.org)

\author{
Acting Editorial Coordinator \\ Peter Lowther (plowther@fieldmuseum.org) \\ Illustration Editor \\ Lisa Kanellos (lkanellos@fieldmuseum.org)
}

\section{Botany}

Associate Editor

Sabine Huhndorf (shuhndorf@fieldmuseum.org)

\section{Zoology}

Associate Editor

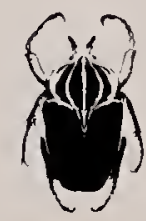

Janet Voight (jvoight@fieldmuseum.org)

Cover photograph: View of the canopy of the primary rain forest at Nanga Tekalit, Sarawak, site of much of the work on which this paper is based. Photograph was taken 22 August 1963 from a tree platform at 25 meters above ground by J. P. Bacon, Jr. 


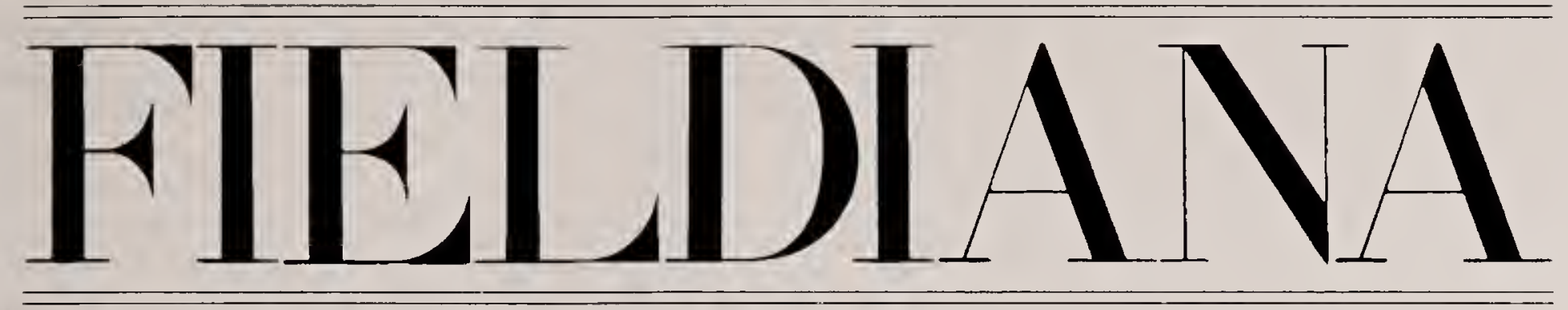

\section{Zoology}

NEW SERIES, NO. 116

\section{Contributions to the Natural History of Seven Species of Bornean Frogs}

Robert F. Inger

Department of Zoology

The Field Museum

1400 South Lake Shore Drive

Chicago, Illinois 60605-2496

U.S. A. ${ }^{1}$

IE-mail: ringer@fieldmuseum.org
UECEIVEL

OCT $1 \cup 2009$

FIELD MUSEUM LIJRA:

Accepted July 14, 2009

Published October 8, 2009

Publication 1552

PUBLISHED BY FIELD MUSEUM OF NATURAL HISTORY 
(c) 2009 Field Museum of Natural History ISSN 0015-0754

PRINTED IN THE UNITED STATES OF AMERICA 


\section{Table of Contents}

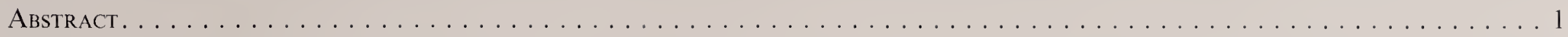

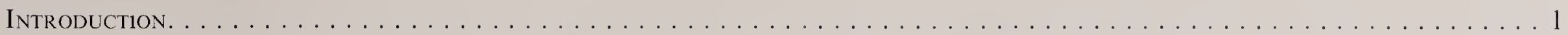

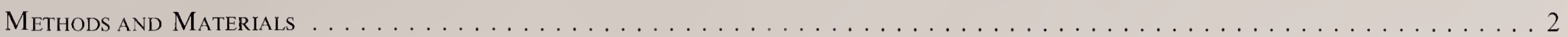

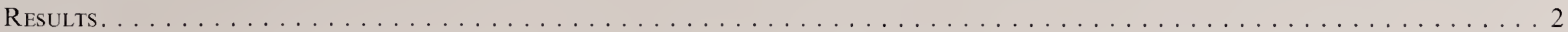

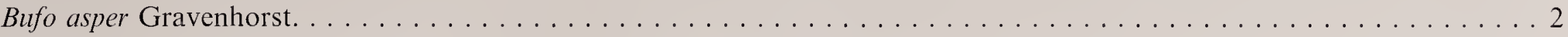

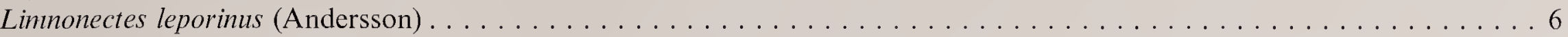

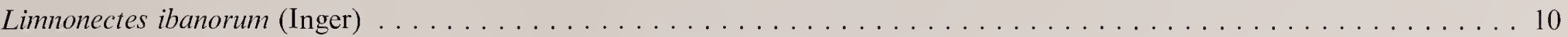

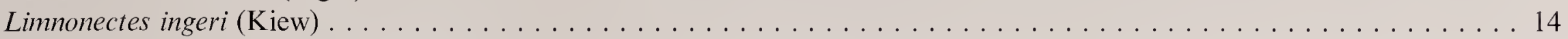

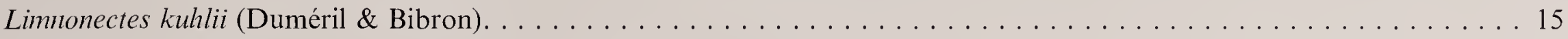

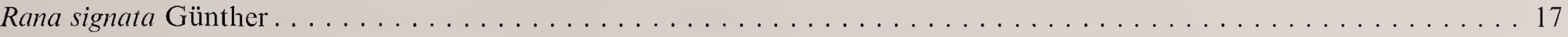

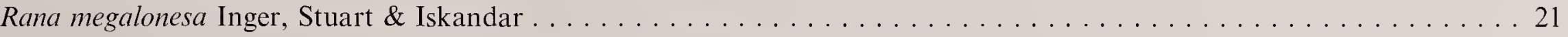

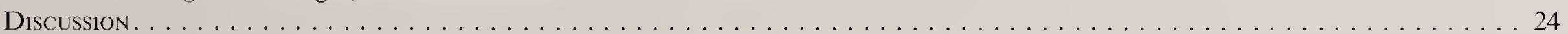

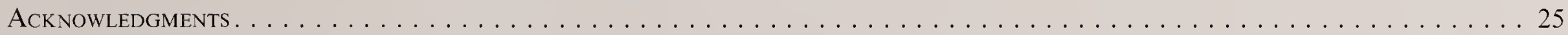

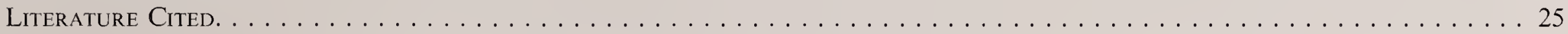

\section{List of Illustrations}

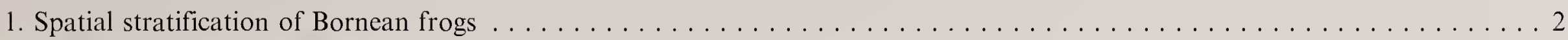

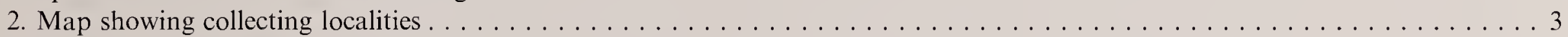

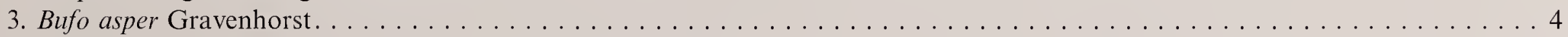

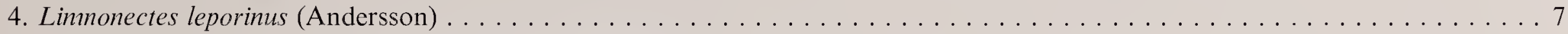

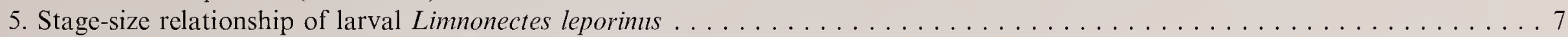

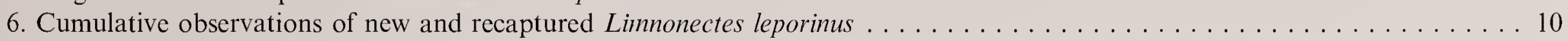

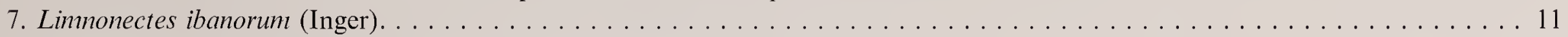

8. Cumulative observations of new and recaptured Limnonectes ibanorum . . . . . . . . . . . . . . . . . . . . 13

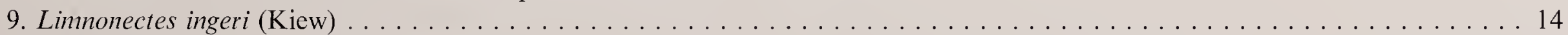

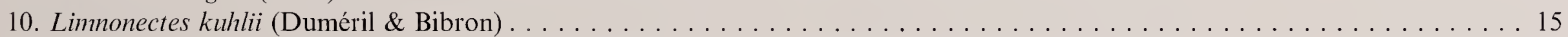

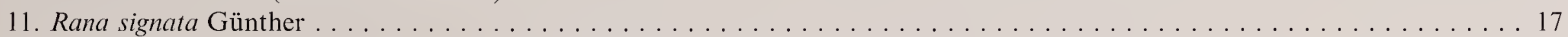

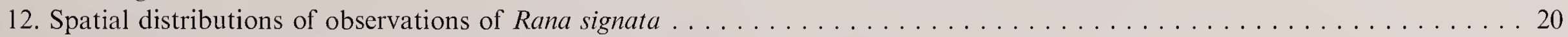

13. Rana megalonesa Inger, Stuart \& Iskandar . . . . . . . . . . . . . . . . . . . . . . . . . . . 21

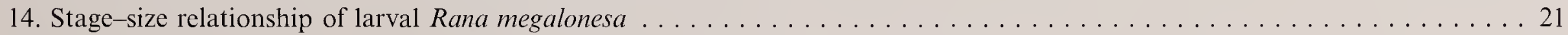

\section{List of Tables}

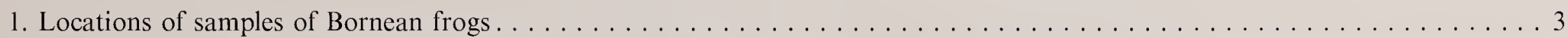

2. Number of Bufo asper observed per night at Nanga Tekalit, Sarawak . . . . . . . . . . . . . . . . . . . . . . .

3. Number of individuals, sex/age distribution, and number of captures of Bufo asper at Nanga Tekalit, Sarawak ........... 5

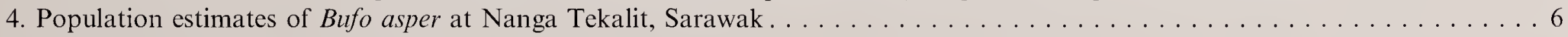

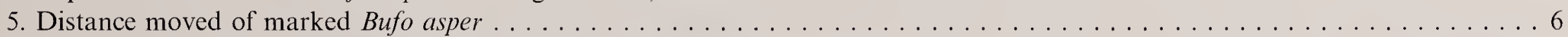

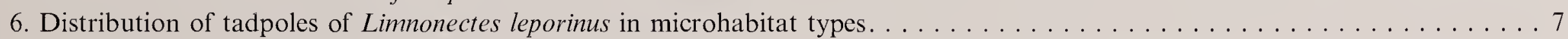

7. Distance from water's edge of Limnonectes leporinus $\ldots \ldots \ldots \ldots \ldots \ldots \ldots$

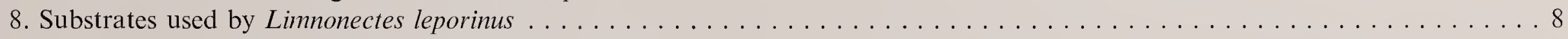

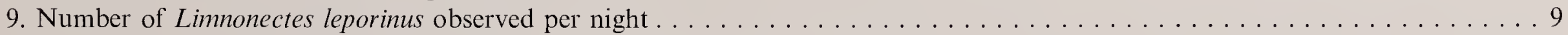

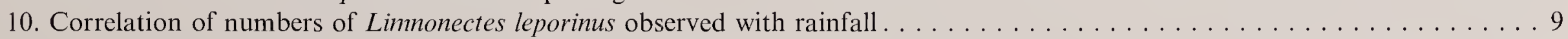

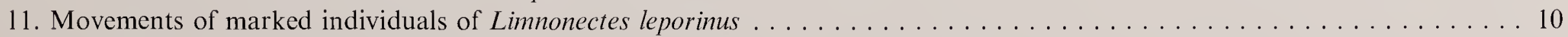

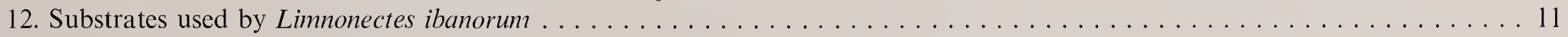

13. Number of Limnonectes ibanorum seen along three streams during three sampling periods. . . . . . . . . . . . . . . 11

14. Relations between numbers of Limnonectes ibanorum collected and stream characteristics . . . . . . . . . . . . . . . 12

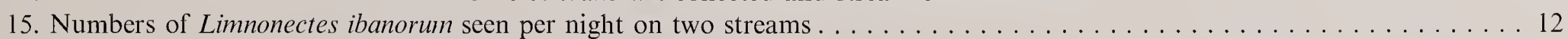

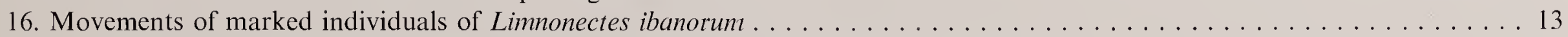

17. Comparison of distributions of three frequently sympatric large species of Limnonectes. . . . . . . . . . . . . . . . . 14

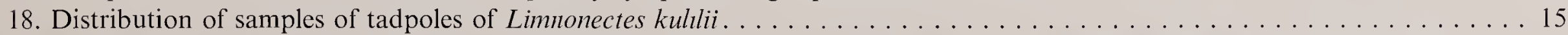

19. Distribution of Limnonectes kuhlii with respect to distributions of larger congeneric species on streams of varying widths ... 16

20. Differences between Limnonectes kuhlii and three larger congeners with respect to bodies of water. . . . . . . . . . . . 16

21. Differences between Limnonectes kultiii and three larger congeners in terms of substrate . . . . . . . . . . . . . . . . . 17

22. Size frequency distribution of Rana signata and $R$. picturata at Nanga Tekalit . . . . . . . . . . . . . . . . . . 18

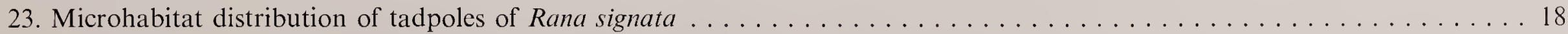


24. Numbers of Rana signata seen at localities in Sarawak and Sabah. . . . . . . . . . . . . . . . . . . . . . . . 19

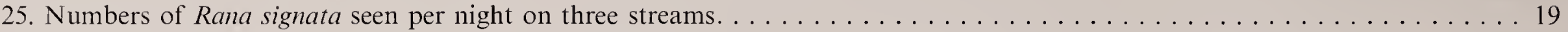

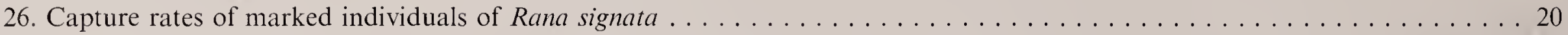

27. Microhabitat distribution of samples of larval Rana megalonesa . . . . . . . . . . . . . . . . . . . . . . 21

28. Vertical positions of adult Rana megalonesa . . . . . . . . . . . . . . . . . . . . . . . . . . . . . . . 22

29. Numbers of Rana megalonesa observed per nocturnal stream transect . . . . . . . . . . . . . . . . . . . . . . 22

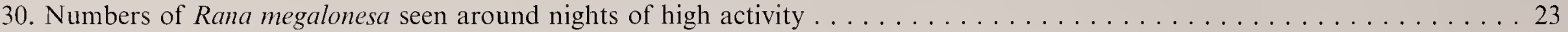

31. Numbers and directions of long moves and net distance for marked frogs of five species $\ldots \ldots \ldots \ldots \ldots$

32. Types of forests occupied by seven riparian-breeding Bornean frogs $\ldots \ldots \ldots \ldots \ldots$ 


\title{
Contributions to the Natural History of Seven Species of Bornean Frogs
}

\author{
Robert F. Inger
}

\begin{abstract}
The anuran fauna of Borneo consists of 156 known species distributed in almost every potential microhabitat in the forested environments that formerly covered the island. Seven of these species are commonly encountered along almost every stream in forests below $750 \mathrm{~m}$ above sea level. Aspects of the natural history of these seven-Bufo asper, Linnonectes ibanorum, L. ingeri, L. kuhlii, L. leporinus, Rana megalonesa, and $R$. signata-are presented based on observations made at 25 localities scattered through Brunei and the Malaysian states of Sabah and Sarawak. Each species shows wide variation in activity (as measured by numbers seen) within and between streams within localities. Recapture of marked individuals of B. asper, L. ibanorum, L. ingeri, and L. leporinus permits estimation of growth rates and time to sexual maturity and, less certainly, to a coarse estimate of the length of reproductive life. Each of these four species showed extremely wide variation among individuals in terms of movements between successive capture points, with some individuals moving very long distances (within a single stream) and others scarcely moving at all. Although all seven species occur within primary and secondary hill forests, two are apparently restricted to such habitats, while the others also occur in flat, alluvial forests. Four have also been found in plantations of Acacia mangium and three in swamp forests.
\end{abstract}

\section{Introduction}

One hundred and fifty-six species of frogs have been reported from Borneo, and the number continues to grow. Although scientific exploration of the anuran fauna of Borneo began in the middle of the 19th century, knowledge of this fauna is mainly taxonomic and biogeographical, with modest amounts of information on ecology (Inger, 1969; Inger et al., 1986) and larval morphology (Inger, 1985). This paper was prepared against the background of two processes: the fragmentation of populations of most species because of the significant development-induced shrinkage of the forest cover and the increasingly difficult political restrictions on field research. The rate at which the forests that once covered all of Borneo shrink threatens the existence of some species (Stuart et al., 2008) and suggests that extinction may now possibly equal or even exceed the rate of discovery of new species.

Given the structural diversity of the tropical forests that once covered all of Borneo, the wide topographic range of this large island, the long geological history of Borneo as a landmass, and the taxonomic diversity of the fauna, it is not surprising that its frog fauna displays a wide diversity of lifestyles. The nonbreeding habits of adult frogs range from the strictly aquatic to the nonaquatic in the horizontal dimension and from the semifossorial to the strictly arboreal in the vertical dimension. Reproductive and developmental habitats range from the strongest currents in rocky streams to the smallest pools of water in tree holes and even in terrestrial and arboreal "nests" lacking water. This spectrum of diversity is summarized in Figure 1.

Adults of 18 species are riparian even when not breeding, only one of them (Barbourula kalimantanensis) known to be completely aquatic and only two (Odorrana hosii and Staurois guttatus) mainly arboreal within the riparian zone. The great majority (131 species) of adults live away from streams when not breeding, with 46 species known to be arboreal and 14 being semiarboreal (Inger, unpubl. data). Coupling of these separate compartments of the fauna occurs during reproduction when, for example, some species that live in the canopy (e.g., Rhacophorus nigropalmatus) descend to near ground level for oviposition and when some nonriparian forest floor species, such as Leptobrachium abbotti, move to streams to breed.

Larvae of 48 species are known to develop in streams, 29 of them in very strong currents. Larvae of one of these species (Rhacophorus gauni) include one form that feeds and one that is endotrophic subsisting on yolk (Inger, 1992). Larvae of 41 species are known to develop in pools of standing waterswamps and rain pools of varying sizes, including water-filled holes in trees or logs.

The developmental sites and patterns of 66 species are currently unknown. In a few cases, educated guesses may be justified. Although larvae of only one species of Kalophrynus, $K$. pleurostigma, have been identified (Inger, 1956), the behavior and microhabitats of adults of all species are so similar that a reasonable assumption is that they have similar developmental patterns - that is, the larvae develop in very small pools of water on the forest floor and are endotrophic. All known larvae of Megophrys from throughout the geographic range of the genus develop in streams so that it is reasonable to assume that the same is true for all of the Bornean Megophrys; in Borneo, only the tadpole of $M$. nasuta has been identified (Inger, 1985). The developmental sites of the 16 Bornean species of the genus Philautus are essentially unrecorded, but what little is known of their developmental patterns suggests that all have direct development (Dring, 1979). Ova of a few Philautus species have been found under forest leaf litter, but it is likely that some oviposit in arboreal 


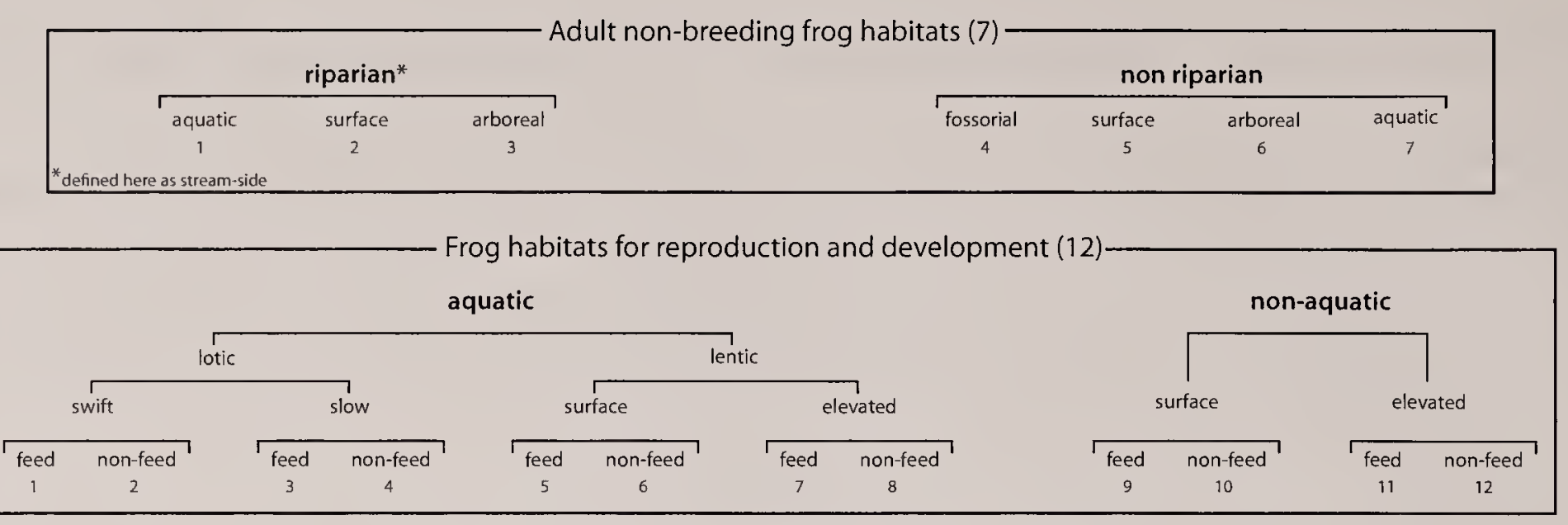

Fig. 1. Spatial stratification of Bornean frogs.

situations. However, one cannot generalize about developmental patterns and larval habitats in genera such as Litnnonectes, which includes some species that oviposit in streambeds (L. leporinus) (Inger, 1985, as Rana blythii) and some that oviposit under leaf litter and then transport tadpoles to small rain pools ( $L$. finchi and $L$. palavanensis) (Inger \& Voris, 1986).

I have thought it useful to summarize information on the lifestyles of several widely distributed and commonly encountered forest species of Bornean frogs. Although these exemplar species are all stream-breeding frogs and represent only a very modest portion of the entire spectrum of the Bornean anuran fauna, they are as a group sufficiently diverse to provide a glimpse of the diversity of at least this ecological portion of the fauna.

\section{Materials and Methods}

The data on which this paper is based were collected over a period of 56 years beginning in 1950 from 27 localities scattered through Brunei and the Malaysian states of Sabah and Sarawak (Table 1 and Fig. 2).

Specimens were collected by several procedures. Adults were caught mainly during nocturnal searches along streams and on nonriparian forest transects. Frogs were also collected by day in forest floor quadrats that were $7.6 \times 7.6 \mathrm{~m}(25 \times$ $25 \mathrm{ft}$ ) at Nanga Tekalit, Sarawak, and $5 \times 5 \mathrm{~m}$ at other sites. Tadpoles were collected by day with dip nets at rain pools, swamps, and slow-current situations in streams. Sampling in these sites was not standardized by number of sweeps; we simply swept a site until no further tadpoles were caught. In moderate to swift current in streams, we searched for tadpoles by means of electrofishing. Frogs were identified, marked, released, and frequently recaptured in a mark-release procedure carried out over a 12-month period (September 1962September 1963) at Nanga Tekalit, Sarawak, on three streams. During the mark-release program, all frogs handled were identified and measured (snout-vent length [SVL]) and their positions relative to marked stations recorded before release. The number of stations per stream varied from 36 to 46 . Distances between stations, measured in feet and converted to meters in the laboratory, varied from 3 to $33.2 \mathrm{~m}$, mean $15.44 \mathrm{~m}$. Tests of error in estimating positions of frogs were not conducted, although there is no reason to suspect bias in those estimates with respect to species or marked frogs. Any movements of marked frogs beyond the limits of the transects (613-660 $\mathrm{m})$ are unknown.

Beginning in 1970, the positions of all specimens collected were recorded according to the system outlined in Inger (1994). All specimens were preserved in formalin and all adults transferred to $70 \%$ ethanol after three to five months. Marked frogs were measured in the field using a ruler graduated in millimeters. Error of field measurements was estimated by comparing measurements on individual frogs captured at intervals of one to three days, assuming that no measurable growth occurred over such short intervals. This procedure was possible for 118 individuals distributed in five speciesLinnonectes ibanorum, L. leporinus, Bufo asper, Rana signata, and $R$. megalonesa. The percent error ranged from $0 \%$ to $11.1 \%$, with means per species varying from $2.0 \%$ to $4.2 \%$. All other frogs and all tadpoles were measured in the laboratory in The Field Museum. Staging of tadpoles used the system of Gosner (1960). Estimates of age based on recaptured frogs ignore the effects of individual variation in growth rates. However, these calculated estimates give at least a first approximation.

\section{Results}

\section{Bufo asper Gravenhorst (Fig. 3)}

This is one of the two largest species of toads in Southeast Asia and adjacent islands, exceeded in size only by $B u f_{O}$ juxtasper. Females of $B$. asper are larger $(95-140 \mathrm{~mm})$ than males $(70-100 \mathrm{~mm})$. The parotoid gland behind the eye is almost circular, usually with the length only slightly greater than the width. The skin is typically toad-like, warty throughout. The color is dark brown to black, without noticeable pattern. We have observed many adults and subadults $(40-50 \mathrm{~mm})$ within $10 \mathrm{~m}$ of banks of forested streams of widths varying from 3 to more than $25 \mathrm{~m}$. Tadpoles develop in streams. We have never seen newly metamorphosed or small $(<30 \mathrm{~mm})$ individuals. Thus, except for the uncertainty about the very small juveniles, it appears that this species is riparian throughout the life cycle.

Distribution in BorneO-Although B. asper has been found at many sites in all major political divisions of Borneo, its abundance seems to vary greatly from area to area. For example, it is very abundant in central eastern Sarawak but rarely seen to the north in western Sabah and is apparently absent in eastern Sabah. All Bornean records are from sites 
TABLE 1. Locations of samples of Bornean frogs. Letters in parentheses correspond to letters on map (Fig. 2).

\begin{tabular}{|c|c|c|c|c|}
\hline Locality & Meters above sea level & Coordinates & Dates of sampling & Days \\
\hline \multicolumn{5}{|l|}{ Sabah } \\
\hline Bukit Kretam (A) & $100^{*}$ & $5^{\circ} 30^{\prime} \mathrm{N}, 118^{\circ} 33^{\prime} \mathrm{E}$ & May-Jun 1950 & 34 \\
\hline Danum (B) & $150-175$ & $5^{\circ} 12^{\prime} \mathrm{N}, 117^{\circ} 50^{\prime} \mathrm{E}$ & Oct-Dec 1986 & 53 \\
\hline Danum & & & Dec 1987 & 12 \\
\hline Deramakot $(\mathrm{C})$ & $100^{*}$ & $5^{\circ} 17^{\prime} \mathrm{N}, 117^{\circ} 33^{\prime} \mathrm{E}$ & Apr-May 1956 & 25 \\
\hline Kalabakan (D) & $50^{*}$ & $4^{\circ} 21^{\prime} \mathrm{N}, 117^{\circ} 32^{\prime} \mathrm{E}$ & May-Jun 1956 & 31 \\
\hline Maliau (E) & $400-750$ & $4^{\circ} 50^{\prime} \mathrm{N}, 116^{\circ} 33^{\prime} \mathrm{E}$ & Aug 1991 & 7 \\
\hline Malutut & $310-360$ & $5^{\circ} 15^{\prime} \mathrm{N}, 115^{\circ} 58^{\prime} \mathrm{E}$ & Nov-Dec 1988 & 21 \\
\hline Marak Parak (F) & 200 & $6^{\circ} 18^{\prime} \mathrm{N}, 116^{\circ} 42^{\prime} \mathrm{E}$ & Oct-Nov 1988 & 23 \\
\hline Mendolong $(\mathrm{G})$ & $650-1350$ & $4^{\circ} 54^{\prime} \mathrm{N}, 115^{\circ} 42^{\prime} \mathrm{E}$ & Nov-Dec 1987 & 25 \\
\hline Mendolong & & & Jul-Aug 1989 & 29 \\
\hline Mendolong & & & Aug 1990 & 22 \\
\hline Poring Sta. & $600-710$ & $6^{\circ} 04^{\prime} \mathrm{N}, 116^{\circ} 41^{\prime} \mathrm{E}$ & Jul 1991-Jul 1993 & 33 \\
\hline Purulon (H) & $340-400$ & $5^{\circ} 13^{\prime} \mathrm{N}, 115^{\circ} 57^{\prime} \mathrm{E}$ & Jun-Jul 1989 & 28 \\
\hline Purulon & & & Sep 1990 & 23 \\
\hline Sapagaya Forest Res. & $50^{*}$ & $5^{\circ} 35^{\prime} \mathrm{N}, 118^{\circ} 04^{\prime} \mathrm{E}$ & Jun-Jul 1950 & 31 \\
\hline Sunsuron (I) & $1250-1500$ & $5^{\circ} 48^{\prime} \mathrm{N}, 116^{\circ} 22^{\prime} \mathrm{E}$ & Aug-Sep 1992 & 18 \\
\hline Tawau Hills Park (J) & $245-270$ & $4^{\circ} 28^{\prime} \mathrm{N}, 117^{\circ} 57^{\prime} \mathrm{E}$ & Jul 1991-Jul 1993 & 33 \\
\hline \multicolumn{5}{|l|}{ Sarawak } \\
\hline Bukit Kana (K) & 250 & $2^{\circ} 39^{\prime} \mathrm{N}, 112^{\circ} 54^{\prime} \mathrm{E}$ & Mar-Apr 2007 & 20 \\
\hline Labang Forest Res. (L) & $50^{*}$ & $3^{\circ} 21^{\prime} \mathrm{N}, 113^{\circ} 27^{\prime} \mathrm{E}$ & Oct 1963-Feb 1964 & 128 \\
\hline Matang & 450 & $1^{\circ} 35^{\prime} \mathrm{N}, 110^{\circ} 14^{\prime} \mathrm{E}$ & Jul 1956 & 10 \\
\hline Sungai Mina & 60 & $2^{\circ} 47^{\prime} \mathrm{N}, 113^{\circ} 10^{\prime} \mathrm{E}$ & Apr 2006 & 15 \\
\hline Nanga Putai & $100^{*}$ & $1^{\circ} 45^{\prime} \mathrm{N}, 113^{\circ} 44^{\prime} \mathrm{E}$ & Aug 1956 & 8 \\
\hline Nanga Tekalit (M) & $150-175$ & $1^{\circ} 37^{\prime} \mathrm{N}, 113^{\circ} 48^{\prime} \mathrm{E}$ & Sep 1962-Sep 1963 & 365 \\
\hline Nanga Tekalit & & & Apr-Jul 1970 & 94 \\
\hline Nanga Tekalit & & & Mar 1984 & 27 \\
\hline Nyabau Forest Res. (N) & $50^{*}$ & $3^{\circ} 14^{\prime} \mathrm{N}, 113^{\circ} 05^{\prime} \mathrm{E}$ & Sep-Oct 1963 & 30 \\
\hline Sg. Penyarai & 40 & $2^{\circ} 33^{\prime} \mathrm{N}, 113^{\circ} 09^{\prime} \mathrm{E}$ & May 2007 & 9 \\
\hline Pesu (O) & 60 & $3^{\circ} 07^{\prime} \mathrm{N}, 113^{\circ} 48^{\prime} \mathrm{E}$ & Mar-Aug 1964 & 155 \\
\hline Samarakan $(\mathrm{P})$ & 36 & $2^{\circ} 56^{\prime} \mathrm{N}, 113^{\circ} 07^{\prime} \mathrm{E}$ & Nov-Dec 2004 & 12 \\
\hline Samarakan & & & Sep 2005 & 6 \\
\hline Samarakan & & & Apr 2007 & 14 \\
\hline Segaham (Q) & $225-610$ & $2^{\circ} 44^{\prime} \mathrm{N}, 113^{\circ} 55^{\prime} \mathrm{E}$ & Apr-Jun 1984 & 61 \\
\hline Tubau Camp & 250 & $3^{\circ} 05^{\prime} \mathrm{N}, 113^{\circ} 39^{\prime} \mathrm{E}$ & Sep-Oct 2005 & 15 \\
\hline \multicolumn{5}{|l|}{ Brunei } \\
\hline Labi $(\mathrm{R})$ & 35 & $4^{\circ} 23^{\prime} \mathrm{N}, 114^{\circ} 27^{\prime} \mathrm{E}$ & Jun 1991 & 6 \\
\hline Tasek Merimbun (S) & 50 & $4^{\circ} 35^{\prime} \mathrm{N}, 114^{\circ} 40^{\prime} \mathrm{E}$ & Jun 1991 & 5 \\
\hline
\end{tabular}

\footnotetext{
* Estimated.
}

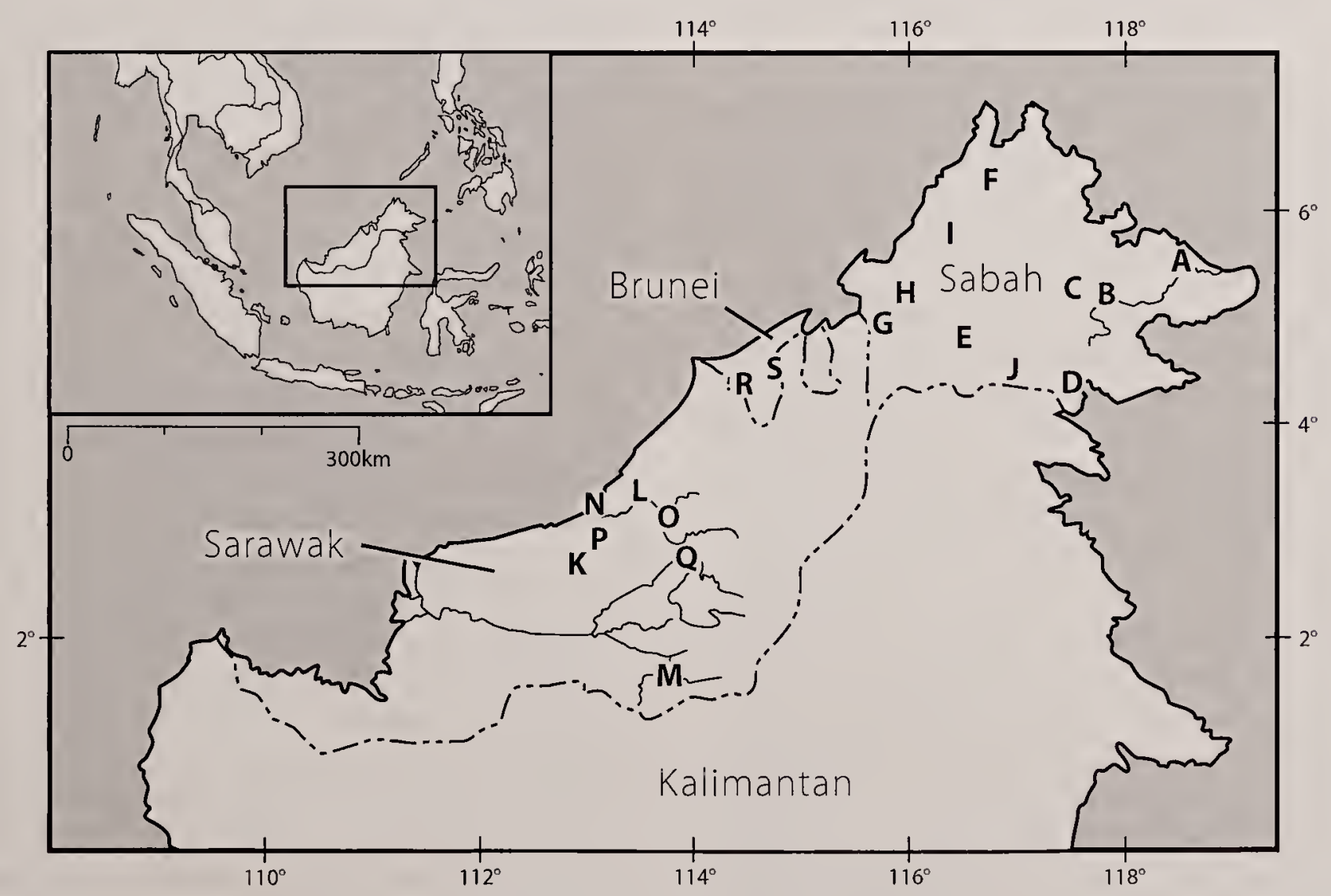

Fig. 2. Map of portion of Borneo, showing collecting localities. Letters on map correspond to those in Table 1. 


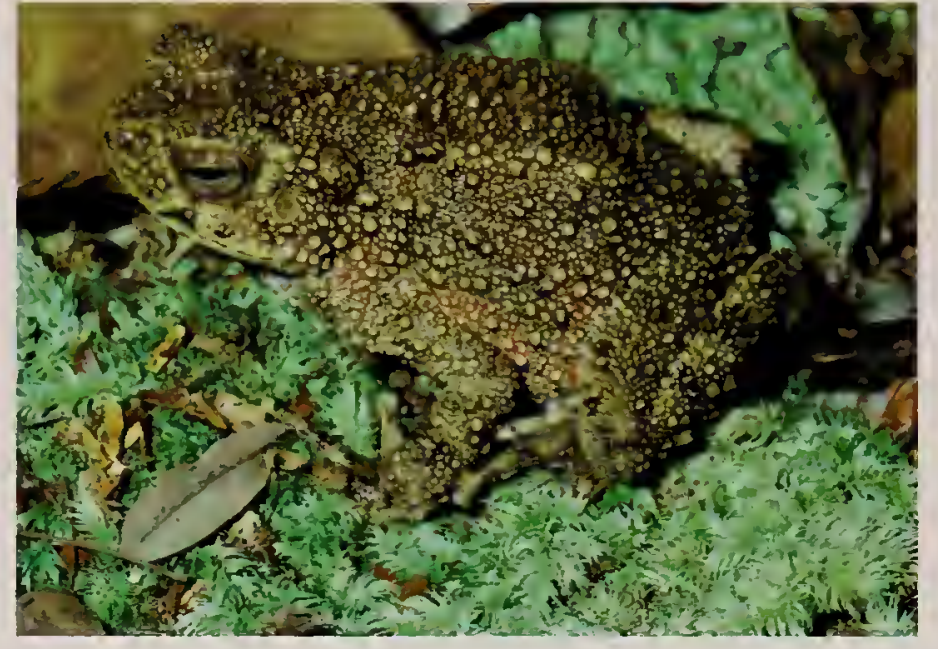

FIG. 3. Bufo asper Gravenhorst

below $400 \mathrm{~m}$ above sea level (ASL). The species is also known from peninsular Thailand and Malaysia, Sumatra, and Java.

The Aquatic Phase-Tadpoles of this species are small and rather stocky, with the body width more than two-thirds of the body length, slightly flattened below, and the tail only slightly longer than the body. The tail is tapered near the end to a broadly rounded tip. The color is black above and on the sides and white below. The tail muscle is black, but the tail fins are only lightly dusted with pigment. The mouth, which is on the underside of the head, has an expanded lower lip (Smith, 1930). Only early stage tadpoles were found. Total lengths were 12 to $15 \mathrm{~mm}$. One of the oddities of these tadpoles is that the long intestine is disposed in distinctly transverse loops rather than the circular spiral typical of most kinds of tadpoles.

Only three sets of tadpoles were found, all in riffles having bottoms varying from gravel and small rocks (less than $15 \mathrm{~cm}$ ) to rock $(30-45 \mathrm{~cm})$. The water was highly oxygenated $(84 \%-$ $94 \%$ of saturation) and warm $\left(26.5^{\circ} \mathrm{C}\right)$. A previous identification (Inger, 1985) of larval B. asper is incorrect.

The Terrestrial Phase-The smallest metamorphosed froglets $(n=3)$ measured 12.5 to $17.9 \mathrm{~mm}$. The largest adult measured was a female $129 \mathrm{~mm}$. Along the three experimental streams at Nanga Tekalit, Sarawak, males measured 70 to $100 \mathrm{~mm}$ (mean $\pm \mathrm{SE}=84.28 \pm 1.03, n=50$ ) and females 80 to $129 \mathrm{~mm}$ (mean $\pm \mathrm{SE}=98.46 \pm 1.55, n=59)$.

Growth AND AGE-All data on this topic are from work on the three experimental streams at Nanga Tekalit, Sarawak. An estimate of error in measurements of these frogs made at night was obtained from measurements made of individuals captured on successive nights, assuming that the crude method of measurement could not resolve the small increment of growth achieved in one day. The error, calculated in this manner, for individuals on Sungai Sekentut varied from zero to 0.077 of $\mathrm{SVL}$ (mean $\pm \mathrm{SE}=0.025 \pm 0.003, n=64$ ). In calculating rates of growth, I treat all negative differences between successive measurements of an individual as zero growth.

All marked juveniles and subadults (SVL $=40-69 \mathrm{~mm}, n=$ 21) showed positive growth. For these immature frogs, limiting calculations to those frogs observed for $\geq 90$ days, the regression of growth rate per day on SVL was $0.32-0.002$ SVL. Based on these values, a $40-\mathrm{mm}$ individual would on average reach $50 \mathrm{~mm}$ in 42 days, a $50-\mathrm{mm}$ individual would reach $60 \mathrm{~mm}$ in 45 days, and a $60-\mathrm{mm}$ individual would reach $70 \mathrm{~mm}$ in 50 days. The smallest metamorphosed individual measured was $12.1 \mathrm{~mm}$ SVL. If the regression line is extrapolated backward to that size, growth from metamor- phosis to $40 \mathrm{~mm}$ would require 100 days, and growth to $70 \mathrm{~mm}$ (near sexual maturity for males) would require on average 238 days and 294 days to reach $80 \mathrm{~mm}$ (near sexual maturity for females).

For marked males, growth all but ceased after sexual maturity at 80 to $85 \mathrm{~mm}$; of 19 males $\geq 80 \mathrm{~mm}$ at first capture and observed for $\geq 90$ days, only three showed positive growth. Females continued to grow until SVL reached approximately $100 \mathrm{~mm}$; all 12 that were 81 to $97 \mathrm{~mm}$ at first capture and observed $\geq 90$ days showed positive growth. Of 13 that were 100 to $129 \mathrm{~mm}$ and observed $\geq 90$ days, only five showed positive growth.

For females $\geq 80 \mathrm{~mm}$ and observed $\geq 90$ days on the three experimental streams at Nanga Tekalit, the regression of growth per day on SVL was 0.253-0.002 SVL. Based on these values, it would take on average 433 days for an $80-\mathrm{mm}$ subadult female to reach the rather usual large size of $110 \mathrm{~mm}$. An estimate of total time from metamorphosis to $110 \mathrm{~mm}$ would be $433+294$ (see above) days, or two years. If the rate of growth of the youngest individuals is underestimated and instead of 100 days to reach $40 \mathrm{~mm}$ is only 40 days, the age at $110 \mathrm{~mm}$ is roughly 1.5 years.

ECOLOGICAL Distribution-Observations of this species were made in primary hill forests, old secondary growth forests, and swamp forests at elevations between 20 and $400 \mathrm{~m}$ ASL. Only five individuals were seen away from stream banks, and three of those were in swamp forest where half the land surface was underwater. All others were seen on banks of streams varying in width from 3 to $60 \mathrm{~m}$ and having beds composed of mud or varying mixtures of sand, gravel, and large rock. Most of the riparian individuals (52\% of 870 for which data are available) were seen within $1.0 \mathrm{~m}$ of water's edge, and only $11 \%$ were seen more than $3 \mathrm{~m}$ from water's edge, the maximum being $7 \mathrm{~m}$. Substrate on which the toads were resting was recorded for 144 individuals. Of these, 33\% were on bare soil or gravel, $15 \%$ were on rocks of varying sizes, and $15 \%$ were on logs. A surprising 29 (20\%) were perched on low $(<1.5 \mathrm{~m})$ vegetation.

DIET-Ants were the principal prey type, occurring in 28 of the 29 stomachs examined. These stomachs contained from eight to 390 ants varying in length from 5 to $22 \mathrm{~mm}$. Other prey types included termites (two stomachs with 98 and 143 termites), Coleoptera (18 stomachs), a variety of other insect orders (none in more than four stomachs), spiders (seven stomachs), and a few other types of small terrestrial arthropods. The largest prey item measured $30 \mathrm{~mm}$. Although most of the species discussed in this paper feed to some extent on ants, none feeds on these very abundant insects to the extent that this bufonid does.

REPRODUCTIVE BEHAVIOR-Bufo asper does not form breeding aggregations. It breeds throughout the year at Nanga Tekalit (Inger \& Bacon, 1968), the only site for which year-round data are available. Clutch size is large, mean of 10 females $=12,792 \pm$ 511 , and does not differ from that of comparable-sized Temperate Zone species (Inger \& Bacon, 1968).

VARIATION IN NUMBERS-Most of our observations pertaining to this topic were made on the three experimental streams at Nanga Tekalit in 1962-1963. During the course of 12 months, 36 night surveys were made on the transects (each $600+\mathrm{m}$ ) of each stream. The numbers of $B$. asper seen on a particular stream on a given night may be a rough measure of activity of this species. That measure demonstrates great variation from stream to stream and within a stream over 
TABLE 2. Number of Bufo asper observed per night on three streams at Nanga Tekalit, Sarawak. All individuals released in 1962-1963, all removed as captured in other years.

\begin{tabular}{|c|c|c|c|c|c|c|c|c|c|}
\hline \multirow[b]{4}{*}{ Number of frogs } & \multicolumn{9}{|c|}{ Stream } \\
\hline & \multicolumn{3}{|c|}{$1962-1963$} & \multicolumn{3}{|c|}{1970} & \multicolumn{3}{|c|}{1984} \\
\hline & Ensurai & Sekentut & Serbong & Ensurai & Sekentut & Serbong & Ensurai & Sekentut & Serbong \\
\hline & \multicolumn{9}{|c|}{ Number of nights } \\
\hline 0 & 1 & & 5 & 1 & & & 2 & & 3 \\
\hline 1 & 1 & & 7 & 1 & & 1 & & 1 & 2 \\
\hline 2 & 1 & & 10 & 2 & 1 & & 1 & 1 & \\
\hline 3 & 10 & & 4 & & 2 & 2 & 1 & 2 & \\
\hline 4 & 4 & & 5 & 1 & 1 & 1 & & & \\
\hline 5 & 7 & 1 & & & & 1 & 1 & & \\
\hline 6 & 5 & & 1 & & & & & & \\
\hline 7 & 2 & 1 & 3 & & & & & 1 & \\
\hline 8 & & 1 & 1 & & & & & & \\
\hline 9 & 1 & 3 & & & & & & & \\
\hline 10 & 2 & 4 & & & 1 & & & & \\
\hline 11 & & 4 & & & & & & & \\
\hline 12 & 1 & 5 & & & & & & & \\
\hline 13 & & 2 & & & & & & & \\
\hline 14 & & 3 & & & & & & & \\
\hline 15 & & 1 & & & & & & & \\
\hline 16 & 1 & 5 & & & & & & & \\
\hline 17 & & 3 & & & & & & & \\
\hline $\begin{array}{l}18 \\
19\end{array}$ & & 1 & & & & & & & \\
\hline 19 & & 1 & & & & & & & \\
\hline Total nights & 36 & 36 & 36 & 5 & 5 & 5 & 5 & 5 & 5 \\
\hline Transect (m) & 613 & 639 & 660 & 660 & 660 & 660 & & & \\
\hline Mean/night & 5.14 & 12.81 & 2.61 & 1.8 & 3.8 & 3.2 & 2.0 & 3.0 & 0.4 \\
\hline Standard error of mean & 0.52 & 0.59 & 0.36 & & & & & & \\
\hline
\end{tabular}

time, both from night to night and from year to year (Table 2). On Sungai Ensurai in 1962-1963, fewer than five individuals were seen on half the 36 nights of surveys, and more than $10 \mathrm{~B}$. asper (maximum 16) were seen on only two of those nights. On Sungai Serbong that year, the maximum seen on a single night was eight, with fewer than four seen on 26 of 36 nights. In contrast, on Sungai Sekentut that year, 12 to 19 individuals were seen on half of the 36 nights. In later years, when frogs were removed rather than marked and released, the numbers seen differed. If one adjusts the number of individuals in 19621963 to the number of transects in the later years (five of 36), the numbers of individuals in 1962-1963 are reduced to 12 for Sungai Sekentut, 12 for Sungai Ensurai, and seven for Sungai Serbong.

Numbers of individuals, sex/age distribution, rates of recapture, and numbers of observations all varied among the three experimental streams in 1962-1963 (Table 3). The population from Sungai Sekentut differed significantly from the others in proportion of males and juveniles, with a higher percentage of males and lower percentage of juveniles on Sungai Sekentut $(t>5.2, P<0.001$, arcsin test of percentages). The number of individuals captured only once, as a percentage of total individuals, varied significantly between the population on Sungai Sekentut and those from the other streams ( $t \geq 2.8, P<0.01$ ), with fewer on Sungai Sekentut never recaptured after the first release. Many more individuals on Sungai Sekentut were captured more than five times, with a maximum of 30 captures (out of 36 visits to the stream). An explanation for the greater number of individuals and of captures per individual on Sungai Sekentut or the greater proportion of males on that stream is not apparent.
The three streams are roughly equal in width and depth, and all were under the canopy of primary rain forest. Sungai Sekentut has the least amount of rocky bottom and Sungai Ensurai the most. Sungai Serbong, which is intermediate in bottom features, had the fewest individuals and the highest percentage of individuals captured just once.

Estimates of population size (Table 4) varied greatly among the three streams. If we take the conservative view that only

TABLE 3. Numbers of individuals and observations, sex/age distribution, and numbers of captures of Bufo asper on three streams at Nanga Tekalit, Sarawak in 1962-1963.

\begin{tabular}{lccc}
\hline & Ensurai & Sekentut & Serbong \\
\hline Length of transect & 613 & 639 & 660 \\
Stream character & most rocky & least rocky & \\
Total observations & 185 & 461 & 94 \\
Total individuals & 84 & 84 & 51 \\
Percentage female & 0.44 & 0.35 & 0.31 \\
Percentage male & 0.10 & 0.55 & 0.13 \\
Percentage juvenile & 0.46 & 0.11 & 0.54 \\
Number captured once & 48 & 30 & 33 \\
$\quad$ Juveniles & 33 & 8 & 21 \\
Females & 12 & 12 & 5 \\
Males & 3 & 10 & 7 \\
Number captured two or & & & \\
$\quad$ more times & 36 & 54 & 18 \\
Juveniles & 6 & 1 & 7 \\
Females & 25 & 17 & 11 \\
$\quad$ Males & 5 & 36 & 0 \\
Number captured more & & & \\
$\quad$ than five times & 4 & 23 & 1 \\
\hline
\end{tabular}


TABLE 4. Population estimates of Bufo asper on three streams at Nanga Tekalit, Sarawak, in 1962-1963.

\begin{tabular}{lccrrr}
\hline Stream & $\begin{array}{c}\text { Census } \\
\text { interval }\end{array}$ & $\begin{array}{c}\text { Length of } \\
\text { interval* }\end{array}$ & $\boldsymbol{n}_{\dagger}^{\dagger}$ & $\boldsymbol{N}_{\ddagger}^{\dagger}$ & SE $(\boldsymbol{N}) \S$ \\
\hline Sekentut & I & 46 & 30 & 31.31 & 1.41 \\
& II & 57 & 26 & 32.87 & 1.26 \\
& III & 59 & 25 & 36.52 & 2.85 \\
& IV & 61 & 21 & 31.01 & 2.55 \\
Ensurai & V & 58 & 24 & 30.70 & 4.56 \\
& I & 41 & 15 & 37.33 & 17.37 \\
& II & 62 & 10 & 49.50 & 25.24 \\
& III & 61 & 13 & 19.80 & 3.02 \\
Serbong & IV & 63 & 6 & 14.58 & 3.93 \\
& V & 60 & 17 & 66.00 & 34.09 \\
& I & 43 & 8 & 12.76 & 6.04 \\
& II & 64 & 7 & 52.00 & 43.42 \\
& III & 63 & 8 & 19.50 & 10.97 \\
& IV & 65 & 6 & 39.00 & 50.57 \\
& V & 62 & 2 & 4.00 & 2.00 \\
\hline
\end{tabular}

* Length of census interval in days.

$\uparrow$ Number of marked individuals released during census interval.

+ Estimated population size during interval.

$\S$ Standard error of population estimate.

those estimates of population size with $N \geq$ three times its standard error are reliable, we conclude that none of the Sungai Serbong estimates are reliable, that only two of the Sungai Ensurai estimates are reliable, but that all the estimates on Sungai Sekentut are reliable. Perhaps the populations on Ensurai and Serbong consisted only or mainly of transients, whereas that on Sekentut consisted of genuine residents. That suggestion is supported by the observations that on Sekentut, $62.5 \%$ of individuals were captured at least two times (maximum 30 times, or 0.83 of the 36 nights) and that 14 $(16 \%)$ were captured more than 10 times. In contrast, fewer than half the $B$. asper marked on the other streams were recaptured (Table 3). Only one individual was captured more than 10 times on Ensurai but none so often on Serbong.

During 1970 and 1984, on five nights of observations in each year on $600-\mathrm{m}$ transects on the same streams, the numbers of $B$. asper seen (and removed as captured) were greater on Sekentut (19 and 15) than on Ensurai (9 and 10) and Serbong (16 and 2).

MOVEMEnTS of INDividuals-All the information on this topic is based on observations of marked B. asper at Nanga Tekalit, Sarawak, in 1962-1963. Table 5 summarizes these data. In addition to the maximum distances shown in the table, several other large movements between successive captures should be mentioned. One female on Sungai Ensurai moved $212 \mathrm{~m}$ upstream during an interval of 14 days, and another female moved $183 \mathrm{~m}$ upstream in 44 days. Both of the large movements of individuals on Sungai Sekentut shown in the table were downstream movements. Three males were captured 21 to 30 times on Sungai Sekentut. The net distances moved by these three were 3.0 to $37.2 \mathrm{~m}$, and the maximum distances between successive capture sites for these three were 19.2 to $61.3 \mathrm{~m}$. The distance moved by individuals seen on successive nights varied widely. For 29 individuals recaptured on successive nights on Sungai Sekentut, the distance between capture sites varied from 0 to $113.7 \mathrm{~m}$ (median $=4.6 \mathrm{~m}, n=$ 65 ). Slightly more than half ( 34 of 65 ) of these distances were downstream, but the two longest were upstream (104.2 and $113.7 \mathrm{~m}$ ). Of 10 overnight distances $>20 \mathrm{~m}$, six were upstream. Thus, the longer overnight distances do not appear to be instances of passive transport by current.

If one assumes that movements of individuals had a random pattern, the more times a particular frog was captured or the larger the number of days between first and last captures, the greater should be net movement. However, there is little relation between net distance and number of days of observation or numbers of captures. The regression coefficients of net distance on either number of captures or number of days were not statistically significant $(P=0.07-0.60)$ for both sexes on all streams. The size of the frog seemed unrelated to net distance, as the regression of net distance on SVL was not significant $(P>0.40)$.

\section{Limnonectes leporinus (Andersson) (Fig. 4)}

This is one of the two largest species of frogs in Borneo, with males reaching lengths greater than $175 \mathrm{~mm}$. The general coloration is medium to dark brown on the back with a few irregular, small black markings. The lips have blackish bars, and there is a short black stripe on the side of the head between the eye and the nostril. The underside is usually unmarked whitish or cream colored, although there may be faint brown marbling on the throat. It is completely riparian, rarely being found more than $10 \mathrm{~m}$ from the banks of medium-sized to very large streams. Tadpoles develop in such streams, and the juvenile frogs remain on the banks of natal streams, feeding and growing, provided that an adult does not eat them. Two other large species of the same genus, $L$. ibanorum and $L$. ingeri, occur with leporinus in parts of Sarawak; the ecological ranges of these species overlap but do not coincide. Limnonectes leporinus had been confused with $L$. blythii (Boulenger) from peninsular Malaysia (Inger, 1966),

TABLE 5. Distance (m) moved of marked Bufo asper on three streams at Nanga Tekalit, Sarawak. All individuals captured at least three times. No males were captured more than two times on Sungai Serbong.

\begin{tabular}{|c|c|c|c|c|c|c|c|}
\hline \multirow[b]{2}{*}{ Stream } & \multirow[b]{2}{*}{ Sex } & \multirow[b]{2}{*}{$n$} & \multicolumn{2}{|c|}{ Net distance* } & \multirow[b]{2}{*}{ Captures } & \multirow[b]{2}{*}{ Maximum distance $\dagger$} & \multirow[b]{2}{*}{ Nmber of days } \\
\hline & & & Range & Median & & & \\
\hline Sekentut & $\mathrm{F}$ & 12 & $3.0-465.4$ & 59.6 & $3-12$ & 465.4 & 74 \\
\hline Sekentut & M & 34 & $0.3-409.4$ & 30.4 & $3-30$ & 444.4 & 31 \\
\hline Ensurai & $\mathrm{F}$ & 15 & $1.5-243.0$ & 28.0 & $3-15$ & 258.8 & 55 \\
\hline Ensurai & M & 2 & $8.2-33.2$ & & 4 & 68.0 & 71 \\
\hline Serbong & $\mathrm{F}$ & 6 & $8.5-138.4$ & 61.3 & $3-8$ & 177.0 & 87 \\
\hline
\end{tabular}

* Distance between first and last capture points.

$\uparrow$ Maximum distance between successive capture points.

$\$$ Number of days between successive captures leading to maximum distance. 


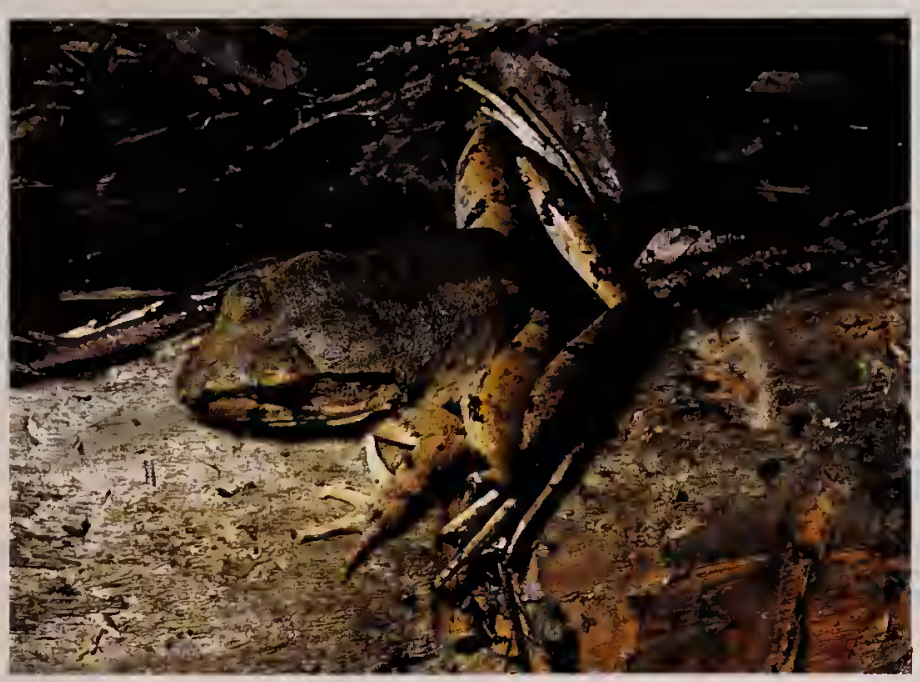

FIG. 4. Limnonectes leporinus (Andersson).

but recent phylogenetic work has shown that the Bornean frogs are distinct (Emerson et al., 2000).

Distribution In BORNEO-This species is known only from Borneo, where it is ubiquitous, having been found in all regions of the island (Inger, 1966; Das, 1995), from near sea level to about $600 \mathrm{~m}$ ASL (Inger \& Stuebing, 2005).

The Aquatic Phase-The tadpoles of this species are moderately slender, with the width of the body about half its length and with the tail about twice the length of the body. The body is mottled with dark brown or black, and the tail has a broad, dark zigzag marking that extends onto both fins. The oral disk is relatively small with only a single row of labial teeth on the upper lip (Inger, 1985). They are most often found in quiet portions of streams, shallow side pools, and drifts of dead leaves (Table 6). Current above these masses of dead leaves may be moderate, but within the leaf drifts, current is negligible. Most of the side pools in which tadpoles of $L$. leporinus were found had no measurable current. These side pools at Tawau Hills Park (Sabah), the only habitats of larval L. leporinus for which readings are available, had $\mathrm{pH}$ of 5.3 to 7.0 (median $=6.0, n=6$ ), temperatures of $22.4^{\circ} \mathrm{C}$ to $23.6^{\circ} \mathrm{C}$, and oxygen at $43.5 \%$ to $62.2 \%(n=2)$ of saturation.

In side pools and leaf drifts, tadpoles of $L$. leporinus commonly co-occur with tadpoles of Ansonia leptopus, Pedostibes hosii, L. ibanorum, and R. signata (Inger, 1985). At these sites, tadpoles of these species overlap greatly in diets (no data are available for Pedostibes) in terms of both the types of organisms and particle sizes ingested (Inger, 1986). However, tadpoles of $L$. leporinuls ingest a larger proportion of
TABLE 6. Distribution of tadpoles of Limnonectes leporinus in microhabitat types. Stages according to Gosner (1960).

\begin{tabular}{lccc}
\hline Microhabitat type & $\begin{array}{c}\text { Number of } \\
\text { samples }\end{array}$ & $\begin{array}{c}\text { Number of } \\
\text { individuals }\end{array}$ & $\begin{array}{c}\text { Range of } \\
\text { stages }\end{array}$ \\
\hline Torrent & 2 & 2 & $27-39$ \\
Riffle & 2 & 3 & 28 \\
Open pool & 3 & 4 & $26-35$ \\
Side pool & 35 & 97 & $25-45$ \\
Leaf drift & 20 & 144 & $25-46$ \\
Pot hole & 8 & 20 & $36-44$ \\
Bank seepage & 1 & 3 & 28 \\
Pool intermittent stream & 1 & 1 & 33 \\
\hline
\end{tabular}

fragments of higher plants than do the other larval forms ( $P \leq$ 0.01 , Kolmagorov-Smirnov test of frequencies). In side pools, all these species of tadpoles feed by creating bottom suspensions that are then ingested (Inger, 1986).

Potential predators of tadpoles in side pools are largely predacious immature insects (mainly nymphal Odonata), as the shallow water limits the size of fishes that can enter and maneuver. We found more fishes in leaf drifts, but these, Mastacembelus and cobitids, were small and probably do not prey on organisms as large as tadpoles.

Most samples of tadpoles of $L$. leporinus consisted of one (27 of 62 samples) or two larvae (10 samples). Only four samples contained more than 10 tadpoles, three with 16 tadpoles, and one with 31. One of the large samples consisted of tadpoles in stages 25 to 39 and may have included tadpoles from two clutches. The others had narrower ranges of developmental stages and probably consisted of larvae from single clutches. Tadpoles in stages 25 to 27 had head-body lengths of 5.3 to $7.9 \mathrm{~mm}(n=13)$ and grew slightly to stages 36 to 37 but very little after that (Fig. 5). Metamorphs in stages 44 to 45 measured 10.0 to $11.6 \mathrm{~mm} \mathrm{SVL}$. There is little basis for estimating time to metamorphosis, although the small size at metamorphosis implies a relatively short larval period, probably no more than four to six weeks.

The Terrestrial Phase-From metamorphosis at less than $15 \mathrm{~mm}$, this species grows to more than $150 \mathrm{~mm}$. Sexually mature males have much larger heads than females, the enlargement involving length, width, and depth and most pronounced behind the eyes (Inger, 1966). The males also develop enlarged fang-like projections at the front of the lower jaw but, unlike the males of most species of ranoid frogs, do

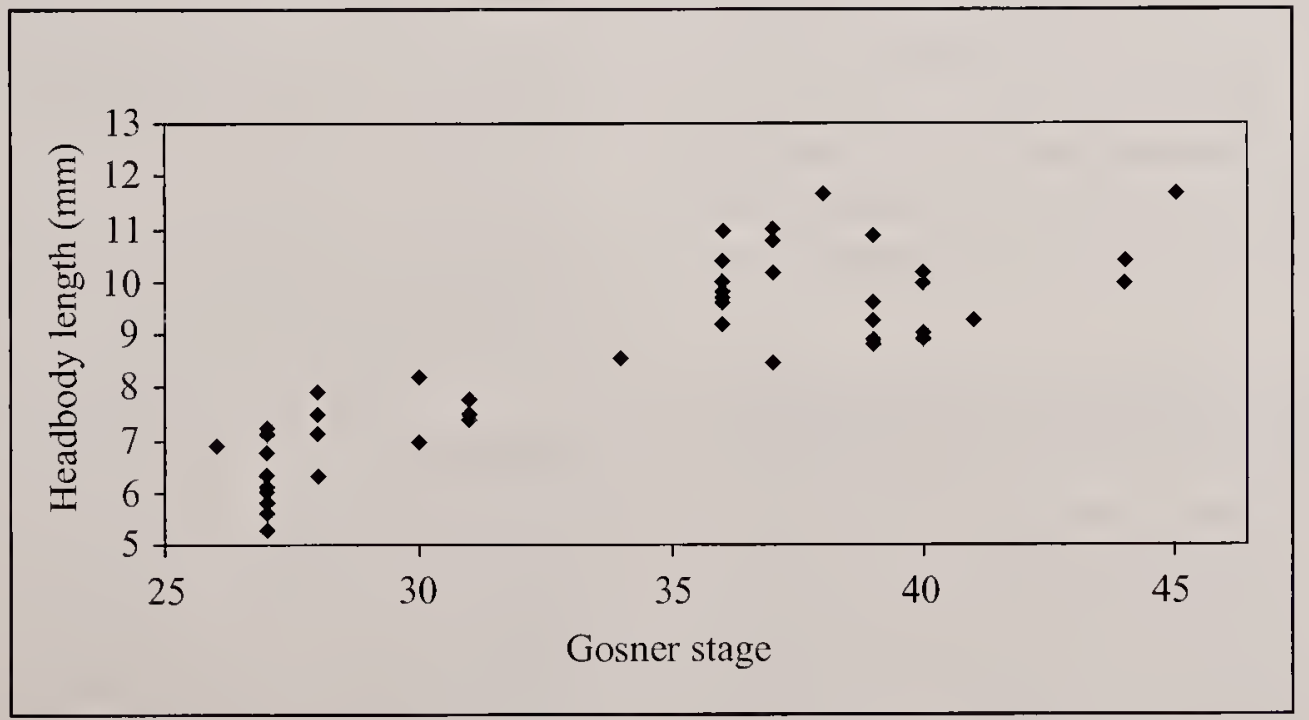

FIG. 5. Stage-size relationship of larval Limnonectes leporinus. 
not develop vocal sacs or nuptial pads on the inner fingers. Enlargement of the head and development of the "fangs" occur when the males reach about $90 \mathrm{~mm}$ SVL. Females reach sexual maturity at about the same size. Half the females in the $82-$ to $89-\mathrm{mm}$ size range have mature oviducts, in contrast to $91 \%$ of those in the $90-$ to $95-\mathrm{mm}$ range (Inger, 1966). The three smallest females with enlarged ova measured 83.9 to $89.3 \mathrm{~mm}$.

Growth AND AgE--These estimates are based on measurements of recaptured frogs at Nanga Tekalit, Sarawak. Error in field measurements, based on differences in measurements of individuals made at intervals of one or two days (assuming no measurable growth in those time frames), varied from $0 \%$ to $8.0 \%$, mean $=2.5 \%$, median $=2.3 \%(n=43)$. Growth rate for juveniles 30 to $49 \mathrm{~mm}$ SVL was $0.131 \mathrm{~mm} /$ day (observation periods $\geq 90$ days, $n=8)$, remained high $(0.134 \mathrm{~mm} /$ day $)$ for frogs 52 to $68 \mathrm{~mm}$ (observation $\geq 90$ days, $n=16$ ), and declined to $0.116 \mathrm{~mm} /$ day for subadults 70 to $79 \mathrm{~mm}$ (observation $\geq 90$ days, $n=15$ ). For 12 small adults, 80 to $89 \mathrm{~mm}$ measured growth was $0.109 \mathrm{~mm} /$ day (observation $\geq 90$ days) and dropped to $0.081 \mathrm{~mm} /$ day for adult frogs 90 to $109 \mathrm{~mm}$ observed more than 90 days $(n=13)$. For 10 large adults 110 to $160 \mathrm{~mm}$ (observation $\geq 90$ days), growth was negligible, $0.047 \mathrm{~mm} /$ day; six of these large frogs showed no measurable growth over observation periods of 90 to 301 days. Given the above rates, a juvenile frog at $40 \mathrm{~mm}$ would need almost one year ( 311 days) to double its size and another 92 days to reach sexual maturity at $90 \mathrm{~mm}$. It was not possible to measure growth rates of smaller juveniles $(15-30 \mathrm{~mm})$, but even assuming a significantly faster rate of growth for these smaller juveniles, on average it probably requires one and onehalf to two years for a $L$. leporinus to reach sexual maturity at $90 \mathrm{~mm}$. Because the rate of growth beyond that size is very slow, the age of the larger individuals $(>120 \mathrm{~mm})$ is probably three or slightly more years and that of the largest individuals $(145-160 \mathrm{~mm})$ several years more. It is likely that the reproductive life of this species is commonly more than two years and may be several times that for some individuals.

ECOlOgical Distribution-Limnonectes leporinus occurs in primary and in at least partly closed secondary growth forests below $750 \mathrm{~m}$ ASL. It is strictly riparian during the terrestrial phase. We have found it along streams varying in width from 2 to $50 \mathrm{~m}$ and with bottoms varying from muddy to rocky, but most were observed on streams having beds of sand, gravel, and rock mixtures. Correlation of numbers observed per transect to stream width is low and not statistically significant $(r=+0.07, P=0.8)$. Frogs of this species remain along stream banks usually within $7 \mathrm{~m}$ of water's edge (Table 7). Males sit slightly closer to water's edge (mean $\pm \mathrm{SE}=2.90 \pm 0.37 \mathrm{~m}, n$ $=40)$ than do females $(4.06 \pm 0.41 \mathrm{~m}, n=55)(t=2.10, P<$ $0.05)$. There is no relationship between the size of frog and distance from water's edge $(b=-0.001 ; P>0.80)$. The substrates on which the frogs usually sit are sand, gravel, and rock (Table 8).

DIET-Limnonectes leporinus feeds on a wide variety of prey -insects of various orders, centipedes, millipedes, decapods, arachnids, earthworms, and small vertebrates (Inger \& Greenberg, 1966). Ants and beetles were the most frequent prey items, followed closely by termites; in effect, these frogs were feeding on the most abundant forms of insects. Seven frogs were found in these 92 stomachs: two Meristogenys sp., two Ansonia sp., one Gastrophrynoides borneensis, one $O$. hosii, and one unidentifiable. Three lizards, identifiable as Spheno-
TABLE 7. Distance from water's edge of observed Limnonectes leporinus along streams in Borneo. Data given are proportions of total in each column.

\begin{tabular}{lccc}
\hline & \multicolumn{3}{c}{ Localities* } \\
\cline { 2 - 4 } Distance $(\mathbf{m})$ & Danum & Segaham & Nanga Tekalit \\
\hline$<1.0$ & 0.449 & 0.186 & 0.285 \\
$1.0-9$ & 0.240 & 0.153 & 0.205 \\
$2.0-2.9$ & 0.123 & 0.136 & 0.190 \\
$3.0-3.9$ & 0.099 & 0.102 & 0.134 \\
$4.0-4.9$ & 0.042 & 0.068 & 0.069 \\
$5.0-5.9$ & 0.033 & 0.068 & 0.034 \\
$6.0-6.9$ & 0.012 & 0.119 & 0.034 \\
$7.0-7.9$ & 0 & 0.017 & 0.018 \\
$8.0-8.9$ & 0 & 0.085 & 0.012 \\
$9.0-9.9$ & 0 & 0.017 & 0.005 \\
$10.0-10.9$ & 0.003 & 0.051 & 0.014 \\
Total observations & 334 & 59 & 649 \\
\hline
\end{tabular}

* Danum Research Centre, eastern Sabah $5^{\circ} 12^{\prime} \mathrm{N}, 117^{\circ} 50^{\prime} \mathrm{E}$; Segaham camp, Belaga District, Sarawak $2^{\circ} 44^{\prime} \mathrm{N}, 113^{\circ} 53^{\prime} \mathrm{E}$; Nanga Tekalit camp, Kapit District, Sarawak $1^{\circ} 38^{\prime} \mathrm{N}, 113^{\circ} 34^{\prime} \mathrm{E}$.

morplus, Tropidophorus, and Aeluroscalabotes, plus one unidentifiable tail, were included. This frog species clearly ingests poisonous prey, such as $O$. hosii and millipedes. The 292 prey items varied from 2 to $120 \mathrm{~mm}$ long (Aeluroscalbotes), with a modal size class of 6 to $10 \mathrm{~mm}$; 16 items were $>50 \mathrm{~mm}$.

ReProductive BeHAvior - This description is based on the observations of Emerson (1992). Males excavate shallow, circular nests in sand or gravel streambeds where the water is no more than 4 to $5 \mathrm{~cm}$ deep. A male sits in the nest after constructing it and waits the approach of a gravid female. As the gravid female enters the margin of the nest, she emits a soft call, and at that point the male mounts the female. As eggs are released, the pair slowly moves in a circular fashion within the nest while kicking the sand and gravel. They intersperse the kicking and circling with quiet intervals, and they may separate for short periods. During this process, the female may repeat the soft calls that initiated the mating. Although the male may respond with similar soft calls, males of this species appear to have no true advertisement calls. At the conclusion of oviposition, the pair kicks more sand and gravel into the nest and then leave. Presumably, after hatching, the young tadpoles wriggle through the bottom gravel to the side pools or leaf drifts, where they complete development.

This species breeds throughout the year in southeastern Sarawak (Inger \& Bacon, 1968). Because the nests are formed in very shallow water (Emerson, 1992), a drop in water level resulting from short rainless intervals can result in desiccation

TABLE 8. Substrates used by Limnonectes leporinus along streams in Borneo.

\begin{tabular}{lccc}
\hline & \multicolumn{3}{c}{ Localities* } \\
\cline { 2 - 4 } Substrate & Danum & Segaham & Nanga Tekalit \\
\hline In water & 11 & 3 & 23 \\
On sand, gravel, soil & 182 & 47 & 285 \\
On rocks & 163 & 8 & 30 \\
On logs & 18 & 2 & 12 \\
On vegetation & 14 & 1 & 3 \\
\hline
\end{tabular}

* See Table 7 
TABLE 9. Number of Limnonectes leporinus observed per night on three streams at Nanga Tekalit, Sarawak.

\begin{tabular}{|c|c|c|c|c|c|c|}
\hline \multirow[b]{2}{*}{ Number of frogs } & \multicolumn{3}{|c|}{$1962-1963$} & \multicolumn{3}{|c|}{1970} \\
\hline & Ensurai & Serbong & Sekentut & Ensurai & Serbong & Sekentut \\
\hline $\begin{array}{r}0 \\
1 \\
2 \\
3 \\
4 \\
5 \\
6 \\
7 \\
8 \\
9 \\
10 \\
11 \\
12 \\
13 \\
14 \\
15 \\
16 \\
17 \\
18 \\
19 \\
20\end{array}$ & $\begin{array}{l}3 \\
\\
3 \\
1 \\
1 \\
3 \\
4 \\
4 \\
1 \\
4 \\
1 \\
2 \\
3 \\
2 \\
2 \\
\end{array}$ & $\begin{array}{l}1 \\
1 \\
3 \\
1 \\
2 \\
3 \\
3 \\
6 \\
3 \\
2 \\
1 \\
2 \\
5 \\
1 \\
1 \\
1\end{array}$ & $\begin{array}{l}1 \\
1 \\
3 \\
3 \\
6 \\
2 \\
2 \\
5 \\
3 \\
2 \\
3 \\
1 \\
3 \\
1\end{array}$ & $\begin{array}{l}1 \\
1 \\
1\end{array}$ & $\begin{array}{l}1 \\
1 \\
1 \\
1 \\
1\end{array}$ & $\begin{array}{l}1 \\
1 \\
1\end{array}$ \\
\hline $\begin{array}{l}\text { Total nights } \\
\text { Transect }(\mathrm{m}) \\
\text { Mean/night } \\
\text { Standard error (mean) } \\
\text { Mean } / 100 \mathrm{~m}\end{array}$ & $\begin{array}{c}36 \\
613 \\
10.69 \\
0.79 \\
1.74\end{array}$ & $\begin{array}{l}36 \\
660 \\
10.05 \\
0.66 \\
1.52\end{array}$ & $\begin{array}{r}36 \\
639 \\
6.36 \\
0.58 \\
1.00\end{array}$ & $\begin{array}{c}5 \\
660 \\
7.0\end{array}$ & $\begin{array}{r}6 \\
660 \\
5.5\end{array}$ & $\begin{array}{c}5 \\
660 \\
10.8\end{array}$ \\
\hline
\end{tabular}

of the nest and its contents. It is not known if rising water levels adversely affect the developing ova.

Clutch size of this species, 1232 to 2472 (Inger \& Bacon, 1968), is relatively small for a species of this size. Comparablesized species of ranids in Europe and North America (e.g., Rana catesbeiana, $R$. clamitans, $R$. ridibunda) have clutch sizes exceeding 5000 (Pope, 1964; Terentjev \& Chernov, 1965). The other unusual aspect of these ova is that they lack a dark animal hemisphere, being uniformly grayish or yellowish.

VARIATION IN NUMBERS-The number of individuals of $L$. leporinus seen on a given stream varied greatly from night to night (Table 9) and from place to place. The numbers observed on the streams at Nanga Tekalit during 1962-1963 were arranged in sequence by date and tested for number of runs above and below the median. On two streams (Ensurai and Serbong), all $L$. leporinus observed were released immediately after capture; on the third stream (Sekentut), all $L$. leporinus were removed as captured. The number of runs above and below median value did not differ from a random distribution for Ensurai $(P=0.54)$ or Serbong $(P=0.44)$ but diverged significantly from random $(P=0.02)$ for Sekentut, which had too few runs. The numbers observed on Serbong and Ensurai were not correlated with rainfall on the day of observation or with rainfall on the day preceding observation (Table 10). Although the observations on Sekentut were consistent with a seasonal pattern, the concentration of low values ( 15 of 18 below the median) in the second half of the year could as well be explained by our removal of a portion of the population beginning during the first half.

Activity by our group on a stream was a potential disturbance of the activities of the frogs and, as a consequence, a factor in the numbers observed. During the year in which we carried out mark and recapture work at Nanga Tekalit, there were four intervals in which we worked on three successive nights and one period in which we worked on four successive nights on each stream. If our activities constituted an inhibitory factor, the numbers observed on the second and third nights in a series should have been smaller than the numbers on the preceding nights. However, as there were five increases, four decreases, and one no change on Sungai Ensurai and equal numbers of increases and decreases on Sungai Serbong, our activities apparently did not affect numbers observed.

The mark-recapture work at Nanga Tekalit, Sarawak, during the year 1962-1963 was conducted during 36 nights grouped into six census intervals on each of three streams. Applying the Jolly-Seber method (Jolly, 1965) of calculating population size (with correction for small samples), the estimates of population size of $L$. leporinus for the first five census intervals (the sixth interval could not be used for this purpose) on Sungai Ensurai were $45.8,86.0,117.5,121.5$, and 93.6 ; standard errors for these estimates were large, ranging from 9.08 for the first to 48.40 for the last estimate. The number of unique individuals seen during these five intervals was 179. The Jolly-Seber population estimates for Sungai Serbong were 113.3, 167.4, 131.8, 111.2, and 174.2; standard errors were large, ranging from 42.76 for the third estimate to 100.41 for the fifth. The number of unique

TABLE 10. Correlation of numbers of Limnonectes leporinus observed with rainfall on day of observation or on day preceding observation at Nanga Tekalit, Sarawak.

\begin{tabular}{lcccccc}
\hline & \multicolumn{2}{c}{ Day of observation } & & \multicolumn{2}{c}{ Day preceding observation } \\
\cline { 2 - 3 } \cline { 5 - 6 } Stream & $\boldsymbol{r}$ & $\boldsymbol{P}$ & & $\boldsymbol{r}$ & $\boldsymbol{P}$ \\
\hline Serbong & +0.18 & 0.31 & & +0.19 & 0.28 \\
Ensurai & +0.10 & 0.59 & & +0.05 & 0.77 \\
\hline
\end{tabular}


A

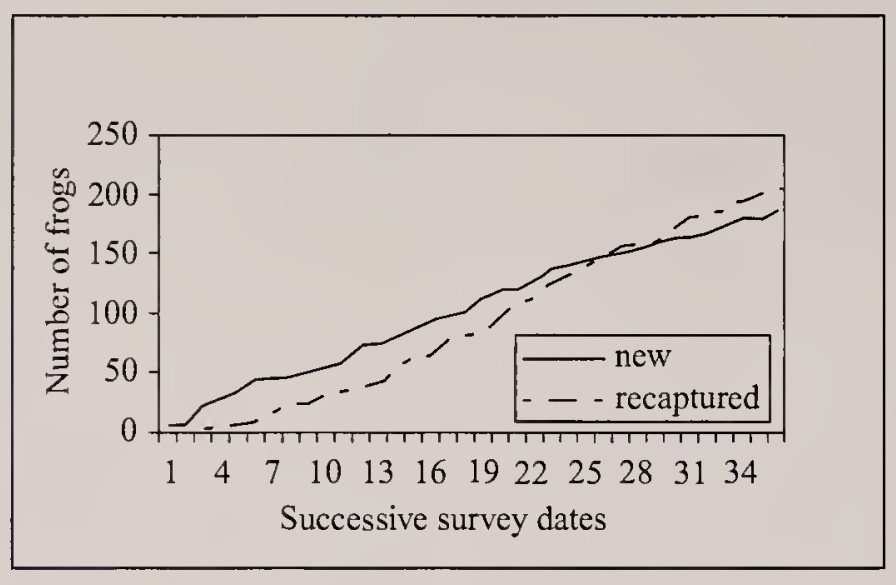

B

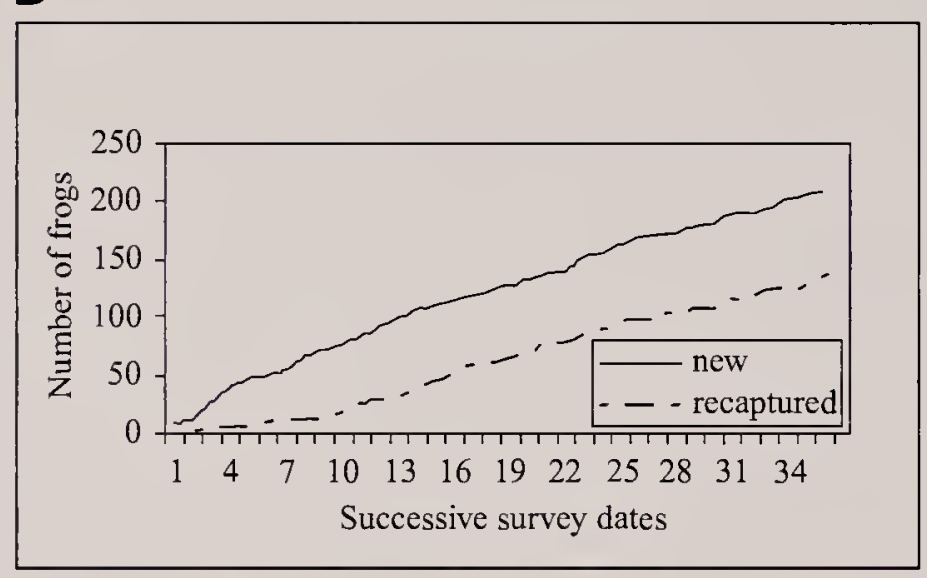

FIG. 6. Cumulative observations of new and recaptured Limnonectes leporinus on (A) Sungai Ensurai and (B) Sungai Serbong, streams at Nanga Tekalit, Sarawak.

individuals seen on Sungai Serbong during these five periods was 198. As the proportion marked of the total number of frogs on a stream increases, the rate of recaptures should increase, with the result that cumulative number of recaptures should increase faster than the cumulative number of newly marked frogs. This was the case on Sungai Ensurai but not on Sungai Serbong (Fig. 6), suggesting that the proportion of the total population marked was higher on the former stream, whereas the total number marked and the population estimates are lower than on Sungai Serbong.
MOVEMENT OF INDIVIDUALS-Movements of individuals were determined by recaptures of marked animals at Nanga Tekalit, Sarawak. Movements of $L$. leporinus varied widely, with maximum distance between capture points ranging from 0 to $591 \mathrm{~m}$ (Table 11). Maximum distance moved was $\leq 20 \mathrm{~m}$ for $62 \%$ of marked frogs. The net distance moved, that is, the distance between the first and last observations of a marked frog, also varied from 0 to $591 \mathrm{~m}$ (Table 11) but with means lower than those for maximum distances. Net distances were $\leq 20 \mathrm{~m}$ for $71 \%$ of recaptured frogs. Mean distances for females were generally smaller than those of males, but the difference was not statistically significant $(t=0.56-1.22, P>$ 0.20 ). Net distance moved was $<1.0 \mathrm{~m}$ for 11 frogs, five females $(81-115 \mathrm{~mm}$ at first capture), three males (100$143 \mathrm{~mm}$ ), and three juveniles $(35-75 \mathrm{~mm})$; two of these frogs were under observation for only two or three days, but the other nine were recaptured over periods of 31 to 166 days. The frog that moved the greatest distance had been under observation 149 days. Assuming a random pattern of movement, net distance should increase with an increase in number of days under observation and number of capture times. However, net distance is not significantly associated with either number of days $(r=+0.06, P=0.49)$ or number of captures $(r=0.01, P=0.9)$. Clearly, the assumption of random patterns of movement is invalid.

\section{Limnonectes ibanorum (Inger) (Fig. 7)}

This creek bank frog is slightly smaller than the related $L$. leporinus, reaching sexual maturity at about $80 \mathrm{~mm}$. The largest individual we saw measured $130 \mathrm{~mm}$. Males reach a larger size than females, as in $L$. leporinus. Limnonectes ibanorum has a stocky body and long, heavily muscled legs. Its skin is rough, the back having many short ridges and round tubercles. Limnonectes ibanorum is not very colorful, being olive green on the back, sides, and upper surfaces of the limbs. The underside is white with large grayish spots or mottling on the chin and throat. The only bright splashes of color are small areas of orange-red or terra-cotta at the corners of the mouth and on the knees and heels in large individuals. This species is

TABLE 11. Movements (m) of marked individuals of Limnonectes leporinus at Nanga Tekalit, Sarawak.

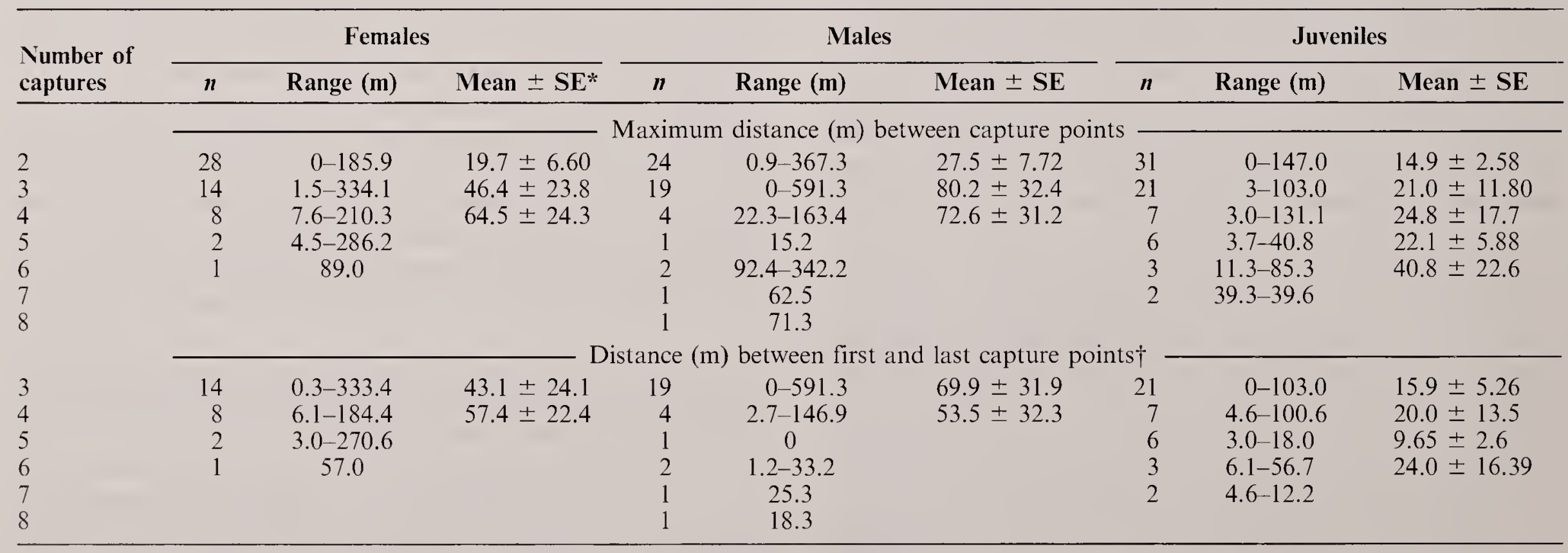

$* \mathrm{SE}=$ standard error.

$\dagger$ Includes only individuals captured at least three times. For individuals captured only twice, distance between first and last captures equals maximum distance between capture points. 


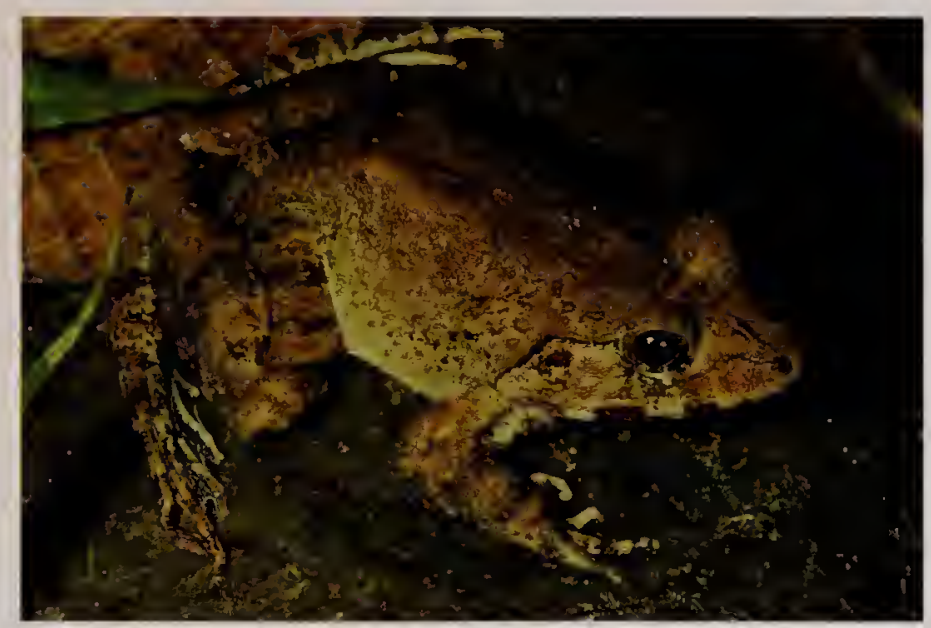

FIG. 7. Limnonectes ibanorum (Inger).

completely riparian; we never found individuals more that $6 \mathrm{~m}$ from the margins of medium-sized streams. Tadpoles develop in quiet portions of these streams, and the small, newly transformed froglets remain on the stream banks while feeding and growing. Although $L$. ibanorum is often found along the same stream banks as the related species, $L$. leporinus and $L$. ingeri, L. ibanorum is more often found along streams having greater areas of rock and lesser areas of sand than the other two species. Its tendency to sit along rocky portions of streams accounts for the name given it by Iban people, "pama batu" (rock frog).

Distribution-This species is endemic to the island of Borneo. It has been recorded from wide areas of hilly terrain at low elevations $(<500 \mathrm{~m})$ in Kalimantan, Sarawak, and Brunei, but it has not been discovered yet in Sabah (Inger, 1966; Das, 1995; Inger \& Stuebing, 2005).

The Aquatic Phase-The tadpoles of $L$. ibanorum are moderate in size (maximum total length about $35 \mathrm{~mm}$ ) and relatively slender, with the body width about two-thirds its length. The body is mottled with brown on the back and sides. The tail is about twice the length of the body (Inger, 1985), lance shaped, and tapered to a moderate point. The tail muscle is speckled with dark spots on its upper surface, and both fins are speckled with smaller dark spots. The oral disk is relatively small and has two rows of labial teeth on the upper lip and three on the lower (Inger, 1985). The tadpoles develop in quiet portions of streams and have been found most often in side pools protected by gravel bars (15 of 41 samples) or in potholes in rocky banks (23 of 41 samples). In the side pools, tadpoles of $L$. ibanorum were found most often with those of L. leporinus and Rana megalonesa; in bank potholes, the commonest co-occurring tadpoles were those of Microhyla petrigena and $R$. megalonesa (Inger, 1985).

In terms of particle size and types of food, the diet of tadpoles of $L$. ibanorum is very similar to that of larval $L$. leporinus but very different from those of the co-occurring larval $R$. megalonesa and $M$. petrigena, both of which ingest much smaller particles and more protists than larval $L$. ibanorum (Inger, 1986). Like larval $L$. leporinus and $R$. megalonesa, tadpoles of $L$. ibanorum hover close to the substrate of their pools, creating and ingesting small clouds of particles (Inger, 1986).

Most samples of larval L. ibanorumum consisted of fewer than six tadpoles of stages 25 to 42 . However, the developmental range within each sample was narrow and consistent with the interpretation that each represented a single clutch. There were in addition five samples consisting of 70 to 101 larvae, of which $81 \%$ were in stage 25 and only two
TABLE 12. Substrates on which Limnonectes ibanorum was observed at Nanga Tekalit, Sarawak, in 1970 and 1984.

\begin{tabular}{lcc}
\hline & \multicolumn{2}{c}{ Proportion of observations } \\
\cline { 2 - 3 } & $\mathbf{1 9 7 0}$ & $\mathbf{1 9 8 4}$ \\
\hline In water & 0.069 & 0.078 \\
On sand, gravel, bare soil & 0.400 & 0.374 \\
On dead leaves & 0.103 & 0.070 \\
On rock & 0.324 & 0.417 \\
On logs & 0.103 & 0.061 \\
Total observations & 145 & 115 \\
\hline
\end{tabular}

older than stage 29. Each of these large sets apparently represented a single clutch with the two older larvae (stages 37 and 38), probably being stragglers from older clutches.

The Terrestrial Phase-Size (SVL) at metamorphosis in this species is approximately 11 to $13 \mathrm{~mm}$ and size at sexual maturity about $80 \mathrm{~mm}$ (Inger, 1966). Maximum size in our large samples is $130 \mathrm{~mm}$. As in L. leporinus, sexually mature males have much larger heads than females and develop enlarged fang-like bony projection at the front of the lower jaw. Males lack vocal sacs and nuptial pads (Inger, 1966).

GROWTH AND AGE-Estimates of growth are based on measurements of recaptured, marked frogs at Nanga Tekalit, Sarawak. Estimated error in field measurements, based on differences in measurements of individuals made at intervals of one or two days (assuming no measurable growth in those time frames), varied from $0 \%$ to $12.9 \%$, mean $=4.2 \%$, median $=3.6 \%(n=24)$. For those individuals observed for at least 90 days, the regression of growth per day on size at first capture was -0.002 on both Sungai Sekentut $(n=15)$ and Sungai Serbong $(n=23)$; the regression coefficient was statistically significant $(P<0.001$ on both streams). With these regression values and by recalculating the growth every $10 \mathrm{~mm}$ after metamorphosis (at $12 \mathrm{~mm}$ ), a newly metamorphosed frog would reach sexual maturity (at $80 \mathrm{~mm}$ ) in about 450 days. Growth rate beyond $80 \mathrm{~mm}$ is very slow; in eight individuals 85 to $109 \mathrm{~mm}$ at first capture and observed for 90 to 294 days, growth varied from 0 to $0.05 \mathrm{~mm} /$ day (mean 0.014 ). At that growth rate, SVL of $100 \mathrm{~mm}$ would be reached approximately two years after the frog reached sexual maturity. It is likely that the reproductive life of this species, like that of $L$. leporinus, lasts for several years.

ECological Distribution-Limmonectes ibanorum occurs along steams within hilly primary rain forest below $500 \mathrm{~m}$. At Nanga Tekalit, Sarawak, it was seen with almost equal frequency on rocks and soil/sand/gravel (Table 12). Among the three experimental streams at Nanga Tekalit, where $L$. ibanorum was abundant, Sungai Ensurai had the largest portion of the bottom in exposed bedrock and Sungai Sekentut the least. The total number of $L$. ibanorum seen on those streams (Table 13) paralleled the rank of the streams in

TABle 13. Number of individual Limnonectes ibanorltm seen along three streams at Nanga Tekalit, Sarawak, during three sampling periods.

\begin{tabular}{lcccc}
\hline Year & Sekentut & Serbong & Ensurai & Transects/stream \\
\hline $1962-1963$ & 95 & 126 & 134 & 36 \\
1970 & 25 & 42 & 54 & 5 \\
1984 & 25 & 26 & 62 & 5 \\
\hline
\end{tabular}


TABLE 14. Relation between numbers of Limnonectes ibanorum collected in 1962-1963 at Nanga Tekalit, Sarawak, and stream characteristics.

\begin{tabular}{|c|c|c|c|c|c|}
\hline Stream & Width (m) & Bed & Transects & Ibanorum & Ibanorum/transect \\
\hline Lawan & 5 & sand/gravel & 18 & 13 & 0.7 \\
\hline Satu & 5 & rock & 11 & 34 & 3.1 \\
\hline Sawa & 5 & sand/rock & 8 & 11 & 1.4 \\
\hline Selubok & 10 & sand/gravel & 17 & 155 & 9.1 \\
\hline Tekalit & 15 & rock & 16 & 60 & 3.8 \\
\hline Mengiong & 60 & sand/rock & 71 & 59 & 0.8 \\
\hline
\end{tabular}

terms of bedrock. This species was also collected on other streams at Nanga Tekalit in 1962-1963, the numbers varying with respect to both stream width and bed characteristics (Table 14). At Segaham, Sarawak, $125 \mathrm{~km}$ from Nanga Tekalit, L. ibanorum was absent along a rocky stream only $2 \mathrm{~m}$ wide (eight transects) and present but not abundant (26 observed during 12 transects) along a rocky stream 25 m wide. This species was not found at a third locality (Labang Forest Reserve) 77 and $180 \mathrm{~km}$ distant from Segaham and Nanga Tekalit, respectively. The terrain at Labang was flat, and the streambeds were muddy (Inger \& Voris, 1993).

Limnonectes ibanorum was never found more than $6 \mathrm{~m}$ from water's edge of the streams at Nanga Tekalit. The distance of this species from water's edge along the three experimental streams at that locality was 0 to $6.1 \mathrm{~m}$ (mean $\pm \mathrm{SE}=0.97 \pm$ $0.08 \mathrm{~m}, n=300$ ). The ecological distribution of $L$. ibanorum differs from that of $L$. leporinus in terms of topographic and substrate features, occupancy of large rivers, and distance from water's edge of streams. At noted above, L. ibanorum was moderately abundant at both Nanga Tekalit and Segaham, both sites with moderate to steep gradient streams, but absent at Labang, which had only low-gradient, muddy streams. In contrast, $L$. leporinus was moderately to very abundant at all three sites ( 52 collected at Labang in 128 days). At Nanga Tekalit, L. ibanorum was seen with almost equal frequency perched on rocks and soil/sand/gravel (Table 12), whereas $L$. leporinus was seen with much greater frequency on soil/sand/gravel ( $81 \%$ of 53 individuals) than on rocks $(9 \%)$. The two species also differ in terms of abundance along very large rivers. During 71 transects on the Mengiong River (>60 m), Nanga Tekalit, spread over 12 months, we observed zero or one L. ibanorum on $74 \%$ of transects, but two to $18 \mathrm{~L}$. leporinus in $95 \%$ of those transects. For L. ibanorum, the mean distance from water's edge along the experimental streams was $0.97 \mathrm{~m}$ (see above), whereas the mean distance for L. leporinus was $2.10 \pm 0.10$ (range $0-9.1 \mathrm{~m}, n=300$ ).

DIET-Limnonectes ibanorum feeds on a wide range of prey, similar to but slightly different from that of L. leporinus (Inger \& Greenberg, 1966; Inger, 1969). The principal taxonomic categories among 131 prey items were abundant insects: termites, ants, and orthopterans. Frogs were not found in the stomachs of L. ibanorum. A small riparian skink, Tropidophorls brookei (SVL $37 \mathrm{~mm}$ ), was found in one stomach. This species preys more heavily on crabs (found in 13 of 50 stomachs examined) than does L. leporinus (crabs in five of 92 stomachs), reflecting the tendency of $L$. ibanorum to perch closer to the water's edge where crabs emerge at night.

ReProductive BeHAVIOR-No observations have been made on the breeding behavior of this species. It is not known if it forms nests as does L. leporinus (see above). However, the species breeds throughout the year at Nanga Tekalit. Although there was variation among months in spermatocyte counts of males and in egg size of females, there was no tendency for high or low months to cluster into a seasonal pattern (Inger \& Bacon, 1968). Clutch size of this species811-1433, mean $=1122$ (Inger \& Bacon, 1968)-is small compared to Temperate Zone ranids of comparable size (Pope, 1964; Terentjev \& Chernov, 1965).

VARIATION IN NuMBERS-The numbers of $L$. ibanorum seen per night varied greatly from stream to stream within a locality (Table 14) but also from night to night within a stream. On the three experimental streams at Nanga Tekalit, the number observed per night in 1962-1963 (36 nights per stream) varied from zero to nine (median $=5$ ) on Sungai Sekentut and from one to 20 (median $=7$ ) on Sungai Serbong (Table 15); all individuals captured were immediately released on those two streams. On Sungai Ensurai, where for experimental purposes individuals were removed as captured after the first three months, the numbers seen per night varied from six to 17 before removal began and zero to seven after that. Arranging the numbers observed per transect by date and testing for number of runs above and below the medians on Sungai Sekentut and Sungai Serbong revealed that the number of runs did not differ from a random distribution. The numbers per night were not correlated with millimeters of rain on the day of observation on either Sungai Sekentut $(r=-0.03, P>0.5)$ or Sungai Serbong $(r=+0.23, P>0.15)$ but were significantly though negatively correlated with rain on the previous day on Sungai Sekentut $(r=-0.42, P=0.01)$ but not on Sungai Serbong $(r=+0.14, P>0.4)$.

The mark-recapture work on the three streams at Nanga Tekalit in 1962-1963 was ordered into six census intervals. Over the course of the year, recapture rates of marked $L$.

TABLE 15. Numbers of Limnonectes ibanorum seen per night on two streams at Nanga Tekalit, Sarawak, in 1962-1963. Lengths of transects: Sungai Serbong $660 \mathrm{~m}$, Sungai Sekentut $639 \mathrm{~m}$.

\begin{tabular}{lcc}
\hline & \multicolumn{2}{c}{ Number of nights } \\
\cline { 2 - 3 } Number of frogs & Sungai Sekentut & Sungai Serbong \\
\hline 1 & 2 & 1 \\
2 & 1 & 2 \\
3 & 3 & 3 \\
4 & 7 & 4 \\
5 & 8 & 5 \\
6 & 4 & 3 \\
7 & 8 & 2 \\
8 & & 6 \\
9 & 2 & 2 \\
10 & & 3 \\
11 & & 2 \\
12 & & 2 \\
14 & & 1 \\
20 & & 1 \\
Mean/night & 4.97 & 7.25 \\
Standard error & 0.35 & 0.63 \\
\hline
\end{tabular}


A

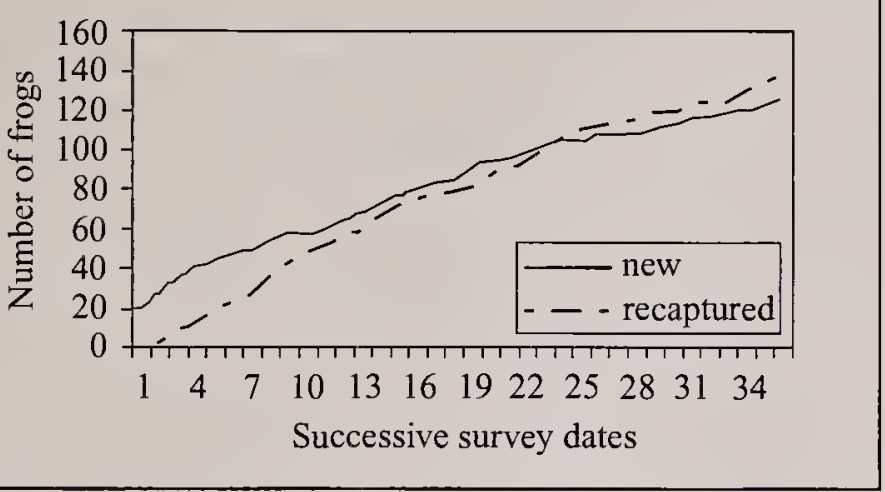

B

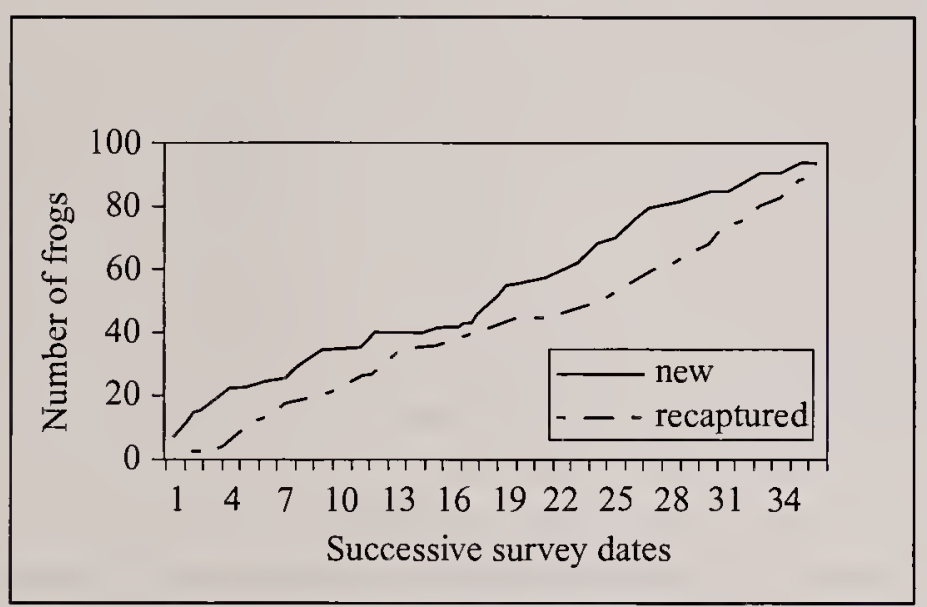

Fig. 8. Cumulative observations of new and recaptured Limnonectes ibanorum on (A) Sungai Serbong and (B) Sungai Sekentut, streams at Nanga Teklait, Sarawak.

ibanorum were $38 \%$ on Sungai Sekentut and $44 \%$ on Sungai Serbong. Population size (Jolly-Seber method [Jolly, 1965]) estimates for the first five census intervals on Sungai Serbong were 92.9, 92.0, 149.0, 62.3, and 21.6; standard errors were large, varying from 12.1 for the fifth interval to 73.2 for the third. The population estimates for the first, third, fourth, and fifth intervals on Sungai Sekentut (low recaptures during the second interval prevented estimation) were 31.5, 52.0, 48.2, and 32.8 , with standard error estimates varying from 7.5 for the first interval to 23.9 for the third. Although the variances of these estimates are large, population sizes were larger on Sungai Serbong than on Sungai Sekentut except for the fifth interval.
The populations of this species on those two streams differed in other ways. The number of unique individuals seen during the five census intervals was larger on Sungai Serbong (117) than on Sungai Sekentut (93). The number of observations per night was also larger on Sungai Serbong (Table 15). The cumulative number of recaptured individuals increased faster than the cumulative number of new individuals on Sungai Serbong (Fig. 8A), suggesting that the proportion marked of total individuals on that stream was increasing. That trend was not seen on Sungai Sekentut (Fig. 8B). The proportion of juveniles to total individuals was higher on Sungai Sekentut $(0.81)$ than on Sungai Serbong (0.63); the difference between these two proportions is statistically significant (arcsin test: $t=2.97, d f>100, P<$ 0.01). Although removal of $L$. ibanorum from Sungai Ensurai prevented estimation of population size, 134 unique individuals of $L$. ibanorum were seen on Sungai Ensurai during that year.

MOVEMENTS OF INDIVIDUALS - Information on movements was derived from the set of marked frogs at Nanga Tekalit in 1962-1963. As with L. leporinus, movements of L. ibanorum between successive observations varied widely, from 0 to $546 \mathrm{~m}$ (Table 16). Seven individuals moved more than $200 \mathrm{~m}$ between successive captures, the equivalent of 2000 times the body length of a frog with a 100-mm snout-vent. Significantly, six of these seven very large movements were made upstream, indicating that these were not simply passive movements effected by the streams' currents. One large movement, $299 \mathrm{~m}$ downstream by an adult male (100 mm SVL), occurred overnight; this change in position may have been a passive movement driven largely by the current.

If movements of these frogs are at random, one would expect that, as the number of observations of a particular individual increases, the chance of a large movement would increase. The maximum distance moved between successive captures did increase with increase in the number of captures $(b=17.916, P=0.001, r=0.30)$. Given random movement, maximum distance moved should also increase with the number of days between successive captures. The regression of distance on days between successive capture is significant $(b$ $=0.363, P=0.039)$, though the correlation is weak $(r=$ $-0.03)$. Size of the frog is not significantly related to maximum distance moved ( $b=0.113, P>0.80, r=0.02$ ).

Net movement, the distance between first and last capture, was not significantly related to number of captures, total days

TABLE 16. Movements (m) of marked individuals of Limnonectes ibanorum at Nanga Tekalit, Sarawak, in $1962-1963$.

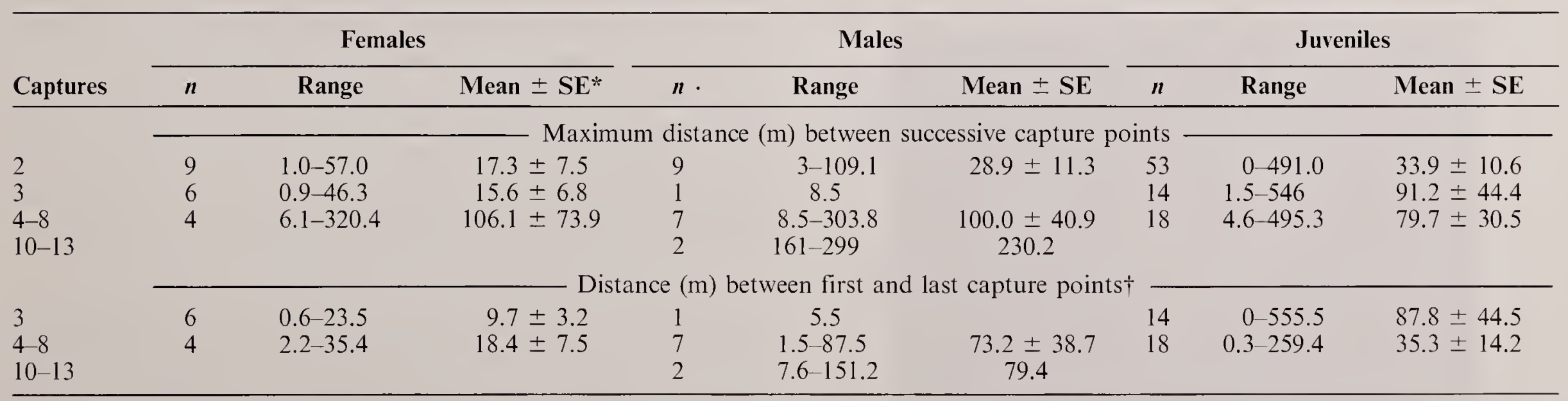

* $\mathrm{SE}=$ standard error.

$\dagger$ Equals maximum distance for frogs captured two times. 
of observation, or size (for all regressions, $P>0.50$ ), suggesting that the pattern of movements is not random. Net distance moved was consistently lower than maximum distance between successive captures (Table 16), again suggesting that movements were not at random. Of 124 frogs recaptured, net movement was downstream for 52, upstream for 67, and no change for five, giving little evidence that current was the major factor in net movement. Small net movements $(<10 \mathrm{~m})$ were four times as numerous as large movements ( $\geq 100 \mathrm{~m}$ ): 52 versus 13 .

The capacity of these frogs for movement along the length of a stream may be illustrated by frog 614 , a male with a 100 mm snout-vent. It was captured 13 times over a period of 232 days. The changes in its position were upstream eight times and downstream four times. Four of these changes exceeded $100 \mathrm{~m}$, two upstream and two downstream, over intervals of one to 61 days. The largest change was $299 \mathrm{~m}$, the one referred to above. The movements downstream may have been passive, effected by current, but the changes in position upstream had to be the result of active movements by the frog. The distance between first and last capture points for frog 614 was downstream $7.6 \mathrm{~m}$.

\section{Lintnonectes ingeri (Kiew) (Fig. 9)}

This large Bornean frog is similar in size to the related species $L$. ibanorun and like the latter reaches sexual maturity at about $80 \mathrm{~mm}$. The largest individual seen was 132-mm SVL. Males become larger than females and have enlarged heads as in L. ibanornm and L. leporinus. The body is stocky, and the legs are long and heavily muscled. The back usually has a few oval or round tubercles. The upper surfaces are grayish to dark reddish brown. Although found in hilly forests like the other large Limnonectes, L. ingeri is more widely distributed (see below). Tadpoles assigned to this species have been found in quiet portions of moderate-sized to small streams.

Distribution-This species is endemic to Borneo and has been recorded from many localities in eastern Sabah and central Sarawak. It has been found at only two places in western Sabah where the topography is steeper than in the east. It has been collected in Brunei, but there is only one record from Kalimantan. It should be widely distributed in the extensive flat areas of southern Kalimantan.

The Aquatic Phase-Tadpoles of this species have been found in water-filled potholes of streambeds and in seepage areas (Inger, 1985). The body is moderately slender and 7.5 to $10 \mathrm{~mm}$ long. The tail is about twice the length of the body.

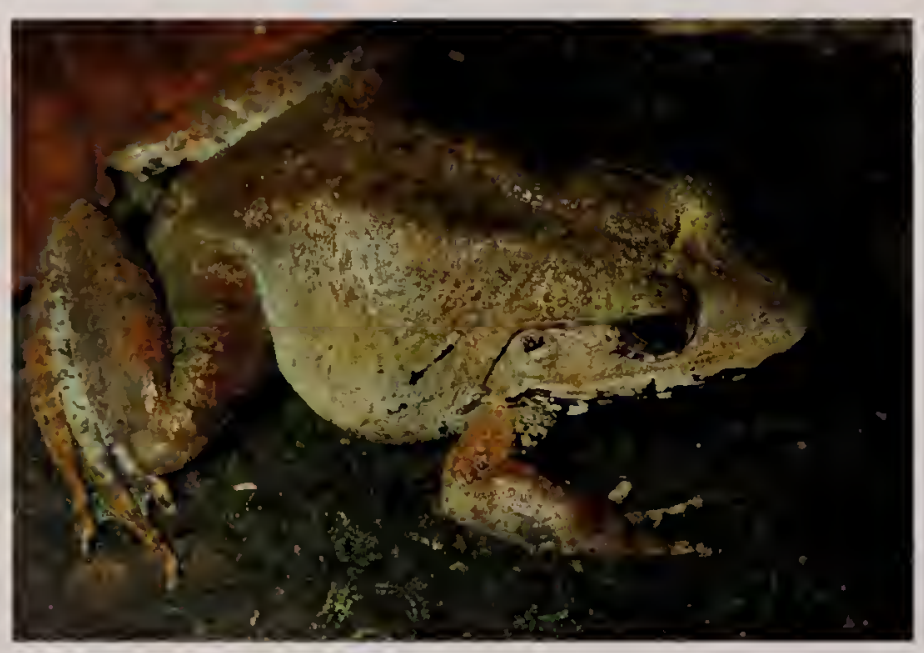

FIG. 9. Limnonectes ingeri (Kiew).
TABLE 17. Comparison of three frequently sympatric large species of Limnonectes in terms of distribution in forest types and distribution with respect to margins of streams.

\begin{tabular}{lccc}
\hline & \multicolumn{3}{c}{ Percentage of individuals } \\
\cline { 2 - 4 } Forest type & leporinus & ibanorutu & iugeri \\
\hline Primary & 72.8 & 93.8 & 23.6 \\
Hilly & 0.1 & 0 & 24.5 \\
Flat & 0 & 0 & 5.8 \\
Swamp & 26.9 & 6.2 & 41.6 \\
Secondary & 2.2 & 0 & 4.6 \\
Acacia planting & 1076 & 340 & 433 \\
Total individuals & & & \\
Horizontal distribution & 1.7 & 0.3 & 13.6 \\
Nonriparian & & & \\
Riparian* & 32.5 & 49.4 & 29.0 \\
$\quad<1.0 \mathrm{~m}$ & 20.9 & 20.0 & 16.6 \\
1-1.9 m & 16.2 & 10.0 & 8.6 \\
$2-2.9 \mathrm{~m}$ & 21.2 & 17.1 & 12.9 \\
$3-5.9 \mathrm{~m}$ & 7.5 & 3.8 & 5.8 \\
6-10 m & 1064 & 340 & 428 \\
\hline Total individuals & & & \\
\hline
\end{tabular}

* Distances (m) from water's edge.

The body is dark gray with no distinct pattern except for a dark crossbar at the root of the tail. The caudal muscle and dorsal fin are speckled with dark pigment. The small oral disk has two rows of labial teeth on the upper lip and three on the lower; the outermost row on the lower lip is only half the length of the adjacent row.

The Terrestrial Phase- Newly metamorphosed individuals have not been found, but as tadpoles and adults are similar in size to those of L. ibanorum, one may assume that metamorphs are similar in size to those of the latter species, that is, 12 to $15 \mathrm{~mm}$.

GrowTH-The following estimates are based on marked frogs at Nanga Tekalit, Sarawak, observed in 1962-1963. For individuals observed for more than 90 days $(n=10)$, the regression of growth per day on size at first capture was 0.213 $0.001 \mathrm{SVL}(P=0.023)$. If size at metamorphosis is $12 \mathrm{~mm}$, a juvenile would reach sexual maturity (at $80 \mathrm{~mm}$ ) in slightly over a year, in approximately 400 days.

Ecological Distribution-Limnonectes ingeri is widely distributed in lowland forests of various types, with maximum observed elevation of this species at $275 \mathrm{~m}$ ASL. Although the majority of those seen were in hilly terrain, 30\% (of 433 individuals) were in flat forest, and of those, 25 were in a freshwater swamp. Twenty frogs were found in plantations of Acacia mangium. Limnonectes ingeri is primarily a riparian species, yet $14 \%$ of the individuals (428) for which details of positions were recorded were found away from streams. Of those seen along streams, more than half $(53 \%)$ were in water or less than $2 \mathrm{~m}$ from the water's edge. Limnonectes ingeri has a wider distribution among forest types than the related species $L$. leporinus and $L$. ibanorum and is more likely to wander from stream banks (Table 17).

DIET-The majority of 62 stomachs containing recently ingested food items held insects of a number of orders (Inger, 1969). However, one contained a centipede $70 \mathrm{~mm}$ long, eight contained crabs with carapace diameters 8 to $33 \mathrm{~mm}$, one contained a small snake (Calamaria lowii), and seven contained frogs. These last consisted of $L$. ingeri (approximately 45 and 
$56 \mathrm{~mm})$, B. asper (18 mm), R. signata (35 mm), small bufonids $(22$ and $30 \mathrm{~mm})$, and one unidentifiable $(40 \mathrm{~mm})$.

MovemenTs-Information on movements of $L$. ingeri is derived from the set of marked frogs at Nanga Tekalit, Sarawak, in 1962-1963. Forty-six frogs were captured two to six times. Maximum distance moved between successive captures was less than $5 \mathrm{~m}$ for 12 frogs over intervals of two to 239 days (median $=30$ days) and exceeded $100 \mathrm{~m}$ over intervals of 21 to 46 days for three frogs. Two of these long movements (133.2 and $142.3 \mathrm{~m}$ ) were downstream and could have been passive, at least partially effected by the current. However, the largest distance $(259.1 \mathrm{~m})$ was upstream over an interval of 32 days.

Maximum distance between successive capture points did not differ among females, males, and juveniles (KruskalWallis test, $P>0.50$ ). Maximum distance between successive capture points $(n=46)$ was not significantly related to SVL $\left(r_{s}\right.$ $=-0.043, P>0.20$ ) but was significantly though negatively correlated with interval in days $\left(r_{s}=-0.42, P<0.01\right)$. However, the distance was significantly and positively correlated with number of captures $\left(r_{s}=0.31, P=0.03\right)$.

Net distance, the distance between first and last capture points, for frogs captured three or more times varied from 0 to $305.4 \mathrm{~m}(n=21)$. Net distance was $<10 \mathrm{~m}$ for 10 of these frogs and $<5 \mathrm{~m}$ for six. The relations between net distance and SVL, number of captures, or number of days between first and last captures were not significant $(P>0.20)$.

If movements of these frogs were at random, distance from an original capture point should increase as a function of both days between captures and number of captures. Maximum distance between successive capture points was positively and significantly related to number of captures, but the other relationships of distance to number of captures and days are not as predicted.

\section{Limnonectes kuhlii (Duméril \& Bibron) (Fig. 10)}

This medium-sized species, reaching sexual maturity at about $40 \mathrm{~mm}$ and a maximum size near $75 \mathrm{~mm}$, is most commonly seen on banks of small to medium-sized streams. Limnonectes kuhlii has a stocky body and relatively short, heavily muscled legs. The skin of its back and legs is rough, with many rounded tubercles, especially in the rear third of the back and on the hind limbs. Within Borneo, there is much variation in the nature of the skin from one regional population to another. This species is olive brown or medium brown on the head, back, and sides, sometimes with indistinct, darker markings on the back. Occasional individuals have a bright orange to yellow stripe down the center of the back from the tip of the snout to the end of the body.

This species is almost exclusively riparian. Only $7 \%$ of the 1154 individuals recorded were not found in a stream or on its banks, and only $1.5 \%$ were found away from any body of water. The great majority of our observations of adults of this species were made along small streams less than $10 \mathrm{~m}$ in width.

DisTRIBUTION IN BORNEO-This species has been reported from all parts of Borneo, from Kinabalu, Sabah $\left(6^{\circ} 5^{\prime} \mathrm{N}\right.$, $\left.116^{\circ} 33^{\prime} \mathrm{E}\right)$, in the north to Palangkaraya, Kalimantan $\left(2^{\circ} 16^{\prime} \mathrm{S}\right.$, $\left.113^{\circ} 56^{\prime} \mathrm{E}\right)$, in the south, and from Gunong Gading, Sarawak $\left(1^{\circ} 44^{\prime} \mathrm{N}, 109^{\circ} 50^{\prime} \mathrm{E}\right)$, in the west to Danum, Sabah $\left(5^{\circ} 12^{\prime} \mathrm{N}\right.$, $117^{\circ} 50^{\prime} \mathrm{E}$ ), in the east. Outside Borneo, L. kuhlii is known from southern China to Java. However, it is likely that this is

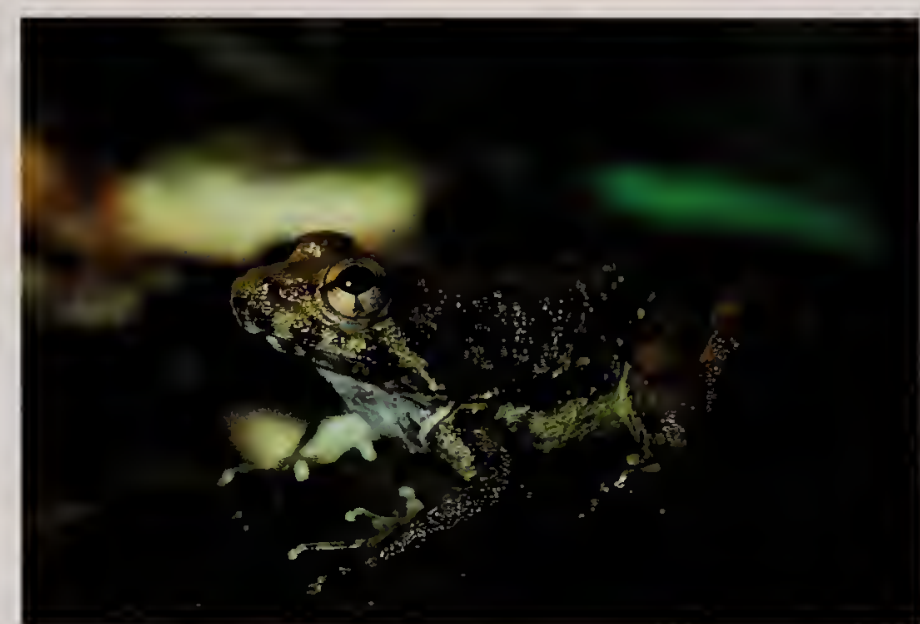

Fig. 10. Limnonectes kuhlii (Duméril \& Bibron).

not a single, widespread species but a set of very similar, closely related ones.

The Aquatic Phase-Tadpoles of L. kuhlii are moderate in size, with a maximum total length of about $45 \mathrm{~mm}$ and rather slender, as is true of the tadpoles of most members of this genus. The body is dusky with a dark spot behind and below the eye and an obscure dark crossband near the end of the body. The tail is lance shaped, ending in an obtuse point, and is almost twice the length of the body (median tail/body = 1.88). The tail is heavily marked with oblique or vertical dark bands. The small oral disk has two rows of labial teeth on the upper lip and three on the lower. The body length in tadpoles of stage 25 had a range of 4.9 to $9.8 \mathrm{~mm}($ mean $=7.2, n=16)$. At stage 36 , the range was 9.7 to $11.6 \mathrm{~mm}$ (mean $=10.42, n=$ 10). Growth was negligible after that; mean body lengths for stages 37 to 42 ranged from 11.0 to $12.1 \mathrm{~mm}$. Metamorphic individuals (stages 4446$)$ measured 8.2 to $12.0 \mathrm{~mm}(n=8)$.

Of the 33 samples with fewer than three larvae, 11 had tadpoles only in stages younger than Gosner stage 30. Two of the largest samples ( $n=22$ and 61$)$ had tadpoles in stages 26 to 38 , and a third large sample $(n=27)$ had tadpoles in stages 25 to 41; all three of these samples may have consisted of more than one clutch. A sample of 13, with tadpoles in stages 26 to 45 probably also included tadpoles from more than one clutch.

The tadpoles develop in quiet open pools or side pools of small streams and seem to be particularly common in shallow, sandy-bottomed, intermittent streams less than $5 \mathrm{~m}$ in width (Table 18). Several of the tadpoles collected appeared to have experienced partially successful attacks by predators. Four tadpoles had one leg completely missing or represented only by a stub. Three tadpoles in that condition had complete, undamaged tails, whereas the tail of the fourth was missing the

TABLE 18. Distribution of samples of tadpoles of Limnonectes kuhlii.

\begin{tabular}{lll}
\hline Type of habitat & Width (m) & Number of samples \\
\hline
\end{tabular}

Intermittent streams

$\begin{array}{rr}<1 & 33 \\ 1-2 & 3 \\ 3-5 & 6\end{array}$

Permanent streams

$1-2$
$3-5$
$\geq 10$

Swamp

Temporary pond

Seepage
6 
TABLE 19. Distribution of Limnonectes kuhlii on streams of various widths compared to distribution of larger congeneric species, $L$. ibanorum, L. ingeri, and L. lepoorinus. Data limited to observations at localities where $L$. kullii and at least one of the larger species occurred.

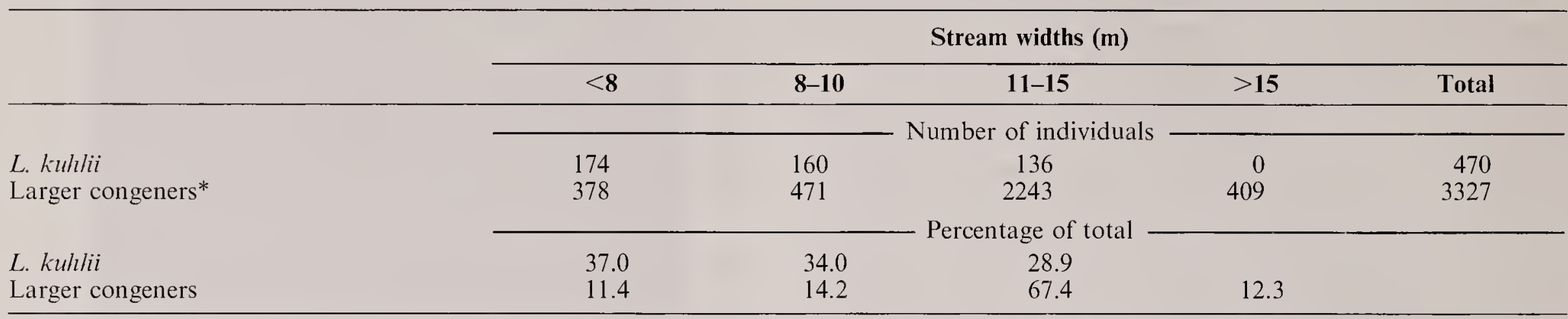

* Linnnonectes ibanorum, L. ingeri, and L. leporinus.

tip. Freshwater crabs, which are relatively abundant in these small streams, are the most likely predators.

The Terrestrial Phase--At metamorphosis, L. kuhlii have SVLs of 11.0 to $12.7 \mathrm{~mm}$ and reach sexual maturity at 41.8 (smallest male with enlarged odontoids) and $46.2 \mathrm{~mm}$ (smallest female with enlarged, convoluted oviduct). Maximum sizes in our samples were 74.3 (male) and 75.9 (female). Mature males, like those of $L$. leporinus and $L$. ibanorum, have larger heads than females and enlarged odontoids at the front of the mandibles (Boulenger, 1920). Males have weak nuptial pads but no vocal sacs.

We have no growth estimates based on recaptured frogs. However, if we consider the growth rates derived for $L$. leporinus in the 40 - to $59-\mathrm{mm}$ size class $(0.13 \mathrm{~mm} / \mathrm{day})$ and assume a faster growth rate for smaller L. kuhlii of $0.18 \mathrm{~mm} /$ day, a frog that metamorphosed at $12 \mathrm{~mm}$ would reach the lower limit for sexually mature males $(41.8 \mathrm{~mm})$ in 155 to 175 days. At a still faster growth rate $(0.20 \mathrm{~mm} /$ day $)$, a minimum estimate for time to sexual maturity is about 150 days.

ECOLOGICAl Distribution-Limnonectes kulthii occurs along streams across a wide altitudinal range in hilly primary or closed canopy secondary rain forests in Borneo. Our observations were made between 20 and $1870 \mathrm{~m} \mathrm{ASL}$, with most $(59 \%)$ being made between 100 and $290 \mathrm{~m}$, where most $(56 \%)$ collecting effort was spent. We saw only six $(<1 \%)$ above $1800 \mathrm{~m}(<1 \%$ of total collecting effort $)$ and only 25 (2.2\%) below $100 \mathrm{~m}$ ( $30 \%$ of collecting effort). Great disparity between numbers observed and collecting effort also occurred at 300 to $590 \mathrm{~m}$, where $14.4 \%$ of total observations were made with only $5.5 \%$ of total collecting effort.

This species was most often observed in water or close to the water's edge of small and medium-sized streams. Of 1154 observations on this species, $91.5 \%$ were made at such sites; only $79(6.8 \%)$ were made at or in ponds and swamps, and only $17(1.4 \%)$ were made away from any kind of aquatic site. Only $7 \%$ of the frogs were seen along intermittent streams. Thirty-one percent of all observations were of frogs actually in the water of streams. Of the frogs seen along streams but not in water, $413(50.6 \%)$ were perched on rocks of various sizes, and $57.6 \%$ were less than $1 \mathrm{~m}$ from the water's edge. A larger proportion of juvenile frogs $(11.3-39.5 \mathrm{~mm})$ were seen at ponds and swamps $(23.5 \%)$ and slightly fewer in water of permanent streams $(14.7 \%)$ than was true of adults and subadults ( $\geq 40 \mathrm{~mm}$ ). Three of 34 juveniles $(31.2-39.5 \mathrm{~mm})$ were found away from any water. Dispersal of juveniles between bodies of water does not appear to be a frequent occurrence.

Airame (1999) found that, at low elevations (500-650 m) on Mt. Kinabalu, activity of $L$. kuhlii was not correlated with rainfall $(r=-0.02)$ but was significantly though negatively correlated ( $r=-0.34, P=0.015$ ) with changing water level in the small streams being monitored.

Its size and usual perch position expose $L$. kuhlii to predation by the larger species $L$. leporinus, L. ibanorum, and $L$. ingeri, which are also riparian and are known to prey on frogs (Inger \& Greenberg, 1966). Avoidance of these predators may explain the greater relative abundance of $L$. kuhlii on smaller streams than those usually frequented by the other, larger congeners (Table 19). Limnonectes kuhlii also differs from those large congeners in horizontal distribution (Table 20) and in substrates occupied (Table 21). The horizontal position most frequently (50.7\%) occupied by the larger congeners was more than $1 \mathrm{~m}$ from water's edge. At localities where L. kuhlii occurred with at least one of these large congeners, $13.1 \%$ of $L$. kuhlii were observed more than $1 \mathrm{~m}$ from water's edge on stream banks in contrast to $24.4 \%$ at localities where none of the large predators occurred.

DIET - Stomach contents of 15 frogs SVL 43.0 to $68.8 \mathrm{~mm}$ included arthropods of 12 orders plus one snail. Ants and

TABLE 20. Differences between Limnonectes kuhlii and the three larger congeners ( $L$. ibanorum, $L$. ingeri, and $L$. leporinus) in terms of distribution with respect to bodies of water. Data limited to observations at localities where $L$. kuhlii and at least one of the larger species occurred. Table gives numbers and percentages of individuals. Sample sizes: $L$. kuhlii $=505$, other congeners $=1048$.

Permanent streams

\begin{tabular}{|c|c|c|c|c|c|c|}
\hline & In water & $<1.0 \mathrm{~m}$ & $\geq 1.0 \mathrm{~m}$ & Intermittent streams & Ponds or swamps & Away from body of water \\
\hline & & & & \multirow{3}{*}{$\begin{array}{l}\text { - Number of individuals } \\
53 \\
16\end{array}$} & & \\
\hline L. kuhlii & 182 & 182 & 71 & & 11 & 6 \\
\hline Congeners & 108 & 364 & 531 & & 6 & 23 \\
\hline L. kuhlii & 36.0 & 36.0 & 17.1 & \multirow{2}{*}{$\begin{array}{l}\text { Percentage of individuals } \\
10.5 \\
1.5\end{array}$} & 2.2 & 1.2 \\
\hline Congeners & 10.3 & 34.7 & 50.7 & & 0.5 & 2.2 \\
\hline
\end{tabular}


TABLE 21. Differences between Limnonectes kullii and the three larger congeners ( $L$. Ibanorum, L. ingeri, and $L$. leporinus) in terms of substrate. Data limited to observations at localities where $L$. kuhlii and at least one of the larger species occurred. Table gives proportions of individuals. Sample sizes: $L$. $k u h l i i=505$, other congeners $=1048$.

\begin{tabular}{lcccccc}
\hline & In water & On soil & On dead leaves & On rocks & On logs & Other $\dagger$ \\
\hline L. kuhlii & 19.8 & 16.2 & 6.5 & 48.3 & 2.6 & 6.5 \\
Congeners & 6.5 & 47.7 & 10.2 & 29.2 & 4.7 & 1.7 \\
\hline
\end{tabular}

* Includes silt, sand, and gravel.

$\dagger$ Minor substrates $(<2 \%$ of $k u / l i i)$ not listed.

termites were the most frequent items (14 each), although all the termites were in a single stomach and the ants distributed in seven. Beetles (eight individuals) were found in six stomachs. Size range of prey was 3 to $40 \mathrm{~mm}$, with 31 of 68 prey items in the 6 - to $10-\mathrm{mm}$ range.

ReProductive BeHAVIOR-Females containing enlarged pigmented ova were collected in all months of the year except January, February, and August in east-central Sarawak (Nanga Tekalit and Segaham). Adult females were not found in those three months. Tadpoles were found in March-May, July-September, and November-December. There was no search for tadpoles during January-February. Limnonectes kuhlii appears to breed in most if not all months of the year.

\section{Rana signata Günther (Fig. 11)}

This is a brightly marked, medium-sized frog (males to $40 \mathrm{~mm}$, females to $56 \mathrm{~mm}$ ), dark brown or black with conspicuous orange, yellow or red markings; a stripe on the side from the tip of the snout, running along the edge of the eyelid and the side to the end of the body, and reddish spots on the back between the stripes. Although it has widened fingertips like an arboreal frog, this species is seen most often on the surface of the soil. It is mainly an inhabitant of primary lowland rain forest and breeds at the edges of clear streams. The life cycle is relatively well known. Tadpoles develop in portions of streams protected from current. At metamorphosis, juveniles hop into forest to feed and grow. When about half grown, they return to streams, where they spend the remainder of their lives.

Distinction between this species and the very similar $R$. picturata in Borneo has only recently been resolved (see Inger \& Stuebing, 2005). As a result, older field records of markrecapture published in the past (Inger, 1969) did not distinguish between the two species. However, the clear difference between the two in SVL (Table 22) determined in

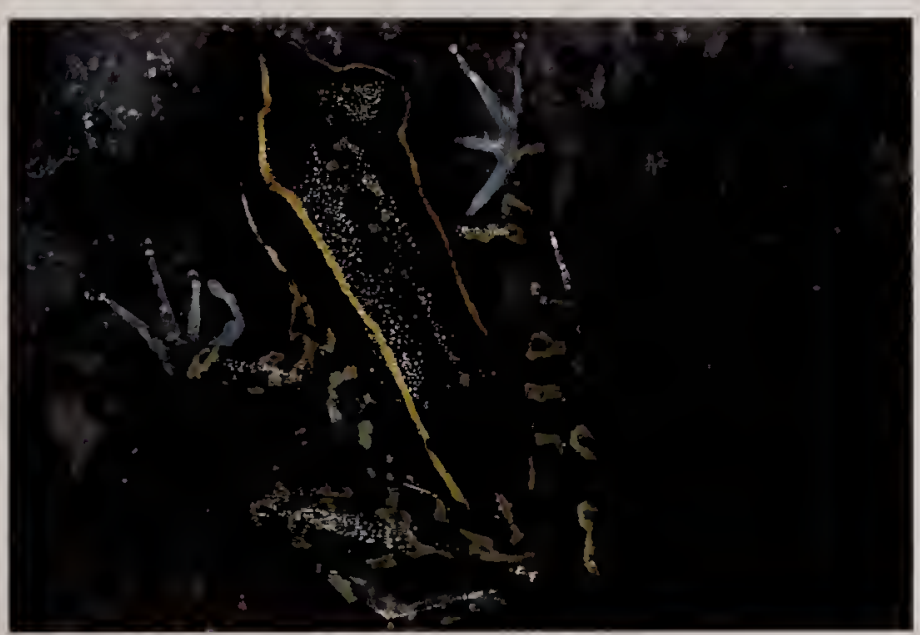

Fig. 11. Rana signata (Günther). the laboratory have permitted correction of old field observations of the two species.

DISTRIBUTION IN BORNEO-Rana signata is widely distributed in Sarawak but is known so far only from two localities in Sabah: Sapagaya Forest Reserve in the east near Sandakan and Mendolong in the southwestern corner of the state. It is also reported from southeastern and western Kalimantan (Veith et al., 2004; Iskandar, pers. comm.) but probably is more widely distributed in that state. Maximum recorded elevation is $700 \mathrm{~m}$ ASL.

The Aquatic Phase-Although larval $R$. signata have relatively slender bodies and tails (Inger, 1985) suggesting the capacity to maintain themselves in moderate current, they are almost always found in quiet portions of perennial streams, most frequently in drifts of dead leaves on streambeds (Table 23). Although the current above the surface of leaf drifts in open pools may be moderate (see below), tadpoles within the leaf drifts live in negligible current. Side pools are portions of streams partially or completely separated from the current; 40 of the 47 such pools for which we have environmental details had no measurable current. Open pools have stronger currents than the other types of microhabitats in which larval $R$. signata were found, yet one open pool in which we caught larval $R$. signata had a current speed of only $1 \mathrm{~m}$ per 28 seconds. Although leaf drifts and side pools are protected microhabitats, they are subject to changes. Typically, leaf drifts remain in place in open pools even after moderate rains because of eddy currents; however, we have seen leaf drifts disappear following alteration of current patterns resulting from streambed changes. Side pools, especially shallow ones, may also disappear because of erosional changes in streambed or because of lowered water levels during short dry periods.

All four samples from open pools were collected in water having the color of strong tea; $\mathrm{pH}$ in these pools varied from 4.6 to 5.1. Although we have no $\mathrm{pH}$ measurements for the other streams, the water in them had no color and presumably had higher $\mathrm{pH}$.

Tadpoles of $R$. signata are part of a group of five larval species living in leaf drifts-A. leptopus, P. hosii, L. leporinus, and Rhacophorus cyanopunctatus (Inger et al., 1986). Less often, tadpoles of $R$. signata co-occur with those of $R$. megalonesa in side pools (Inger, 1985, listed as $R$. chalconota). Leaf drifts constitute an environment rich in the types of food, such as, blue-green algae, fungi, and decaying fragments of tracheoid plants, used by these species of tadpoles (Inger, 1986). Leaf drifts are also very large (often $100 \mathrm{~cm}$ in diameter and $10-25 \mathrm{~cm}$ deep) relative to the numbers of tadpoles found. Consequently, there is probably little interspecific competition among these larvae.

Most samples (13 of 25) contained only a single tadpole, and only three contained $>10$; the maximum was 15 . One 
TABLE 22. Frequency distribution of snout-vent length (SVL, mm) of Rana signata and R. picturata at Nanga Tekalit, Sarawak.

\begin{tabular}{|c|c|c|c|c|c|}
\hline \multicolumn{3}{|c|}{ Males } & \multicolumn{3}{|c|}{ Females } \\
\hline SVL & signata & pictullata & SVL & signata & picturata \\
\hline & & & 46 & 2 & \\
\hline 30 & 1 & & 47 & 1 & \\
\hline 31 & & & 48 & 3 & \\
\hline 32 & 1 & & 49 & 4 & 2 \\
\hline 33 & 1 & & 50 & 8 & \\
\hline 34 & 16 & & 51 & 11 & \\
\hline 35 & 23 & & 52 & 11 & \\
\hline 36 & 29 & & 53 & 3 & \\
\hline 37 & 35 & & 54 & 3 & \\
\hline 38 & 20 & & 55 & 3 & \\
\hline 39 & 5 & 1 & 56 & & 1 \\
\hline 40 & 2 & 1 & 57 & & 2 \\
\hline 41 & & 7 & 58 & & 1 \\
\hline 42 & & 11 & 59 & & 1 \\
\hline 43 & & 14 & 60 & & 2 \\
\hline 44 & & 21 & 61 & & 1 \\
\hline 45 & & 11 & 62 & & 3 \\
\hline 46 & & 7 & 63 & & 2 \\
\hline 47 & & 3 & 64 & & 1 \\
\hline 48 & & 1 & & & \\
\hline Total & 133 & 77 & & 49 & 16 \\
\hline Range & $30.0-40.2$ & $39.7-48.1$ & & $46.8-55.9$ & $49.3-64.6$ \\
\hline Mean $\pm \mathrm{SE}^{*}$ & $36.23 \pm 0.14$ & $43.64 \pm 0.21$ & & $50.98 \pm 0.30$ & $59.63 \pm 0.75$ \\
\hline
\end{tabular}

$* \mathrm{SE}=$ standard error.

sample consisted of 14 in stage 25 , with a head-body size range of 3.6 to $5.2 \mathrm{~mm}$. A second sample consisted of nine tadpoles in stage 25 measuring 3.8 to $5.1 \mathrm{~mm}$. Both of these samples almost certainly represent single, relatively young clutches. A sample of 15 included tadpoles in stages 25 to 38 . As the five in stage 25 measured 5.6 to $9.1 \mathrm{~mm}$, probably they were older than those in the two clutches previously mentioned, and the more advanced larvae may have been faster-growing individuals of the same clutch. As clutch size of $R$. signata is greater than 500 (see below), the small number of tadpoles per sample suggests heavy predation. Larval $R$. signata have conspicuous dermal glands resembling those of larval $R$. chalconota, which are known to be poisonous and to deter vertebrate predators (Liem, 1961). Although many aquatic insects, including predaceous kinds, occur in the types of microhabitats used by larval $R$. signata, tadpoles of $R$. megalonesa living in some of the same types of microhabitats are exposed to the same kinds of predators yet seem not to experience the same intensity of predation.

Head-body lengths of tadpoles in stage 25 ranged from 3.6 to $9.2 \mathrm{~mm}(n=57)$; those in stages 26 to 28 from 8.3 to $9.7 \mathrm{~mm}(n$ $=8)$, those in stages 36 to 40 from 11.3 to $13.2 \mathrm{~mm}(n=6)$, and those in stages 41 to 44 from 12.1 to $13.5 \mathrm{~mm}(n=5)$. Thus, most growth takes place in stage 25 and very little after stage 36 . The rapid growth in early development stages, especially in stage 25 , may represent the effect of strong predator-driven

TABLE 23. Distribution of tadpoles of Rana signata.

\begin{tabular}{lcc}
\hline Microhabitat type & Number of samples & Number of individuals \\
\hline Riffle & 1 & 1 \\
Open pool & 4 & 18 \\
Side pool & 8 & 17 \\
Leaf drift & 10 & 65 \\
Pothole & 2 & 2 \\
\hline
\end{tabular}

selection. Caldwell et al. (1980) have shown that survival in at least some species of tadpoles depends on rapid growth to less vulnerable sizes as a means to escape gape-limited predators. Predaceous aquatic insects, such as immature Odonata, which are common in all stream microhabitats in Borneo, probably have their greatest impact on smaller tadpoles. There is no information on time required for larval development, but in view of the size at premetamorphic stages (40-42), it is probably no longer than two months.

The Terrestrial Phase--The two smallest transformed individuals, 17.2 to $17.4 \mathrm{~mm} \mathrm{SVL}$, had streaks of melanophores at the end of the body representing the vestige of the recently resorbed tail. Males lacking nuptial pads measured 28.3 to $37.3 \mathrm{~mm}$. The size range among males or females is not great, roughly $10 \mathrm{~mm}$ in both sexes. At Nanga Tekalit, Sarawak, the site of the largest sample, males with nuptial pads measured 30.0 to $40.2 \mathrm{~mm}$, mean $\pm \mathrm{SE}=36.23 \pm 0.14$ (Table 22). At the same site, adult females, that is, those with strongly convoluted oviducts, measured 46.8 to $55.9 \mathrm{~mm}$, mean $\pm \mathrm{SE}=50.98 \pm 0.30$ (Table 22). Twenty-five marked adult males were observed for periods $>90$ days. The differences between field measurements at first and last sightings for these 25 were -3 to $+1 \mathrm{~mm}$. Six of these males were observed for periods between 180 to 332 days, and all showed slight negative changes in size. Only two females were observed for more than 90 days (maximum 119 days); changes in size were 0 and $-1 \mathrm{~mm}$. Probably all these apparent changes in size fall within the limits of accuracy of measurements made at night as the frogs were captured. These data indicate that little or no growth occurs after sexual maturity is reached and that little of the variation among individuals seen in Table 22 is age related.

Age at which sexual maturity is reached is unknown, but a rough estimate can be made based on size of tadpoles in premetamorphic stages. Tadpoles reach 13 to $14 \mathrm{~mm}$ headbody length (see above). Time required to double that length and approach the size of the smallest mature male is probably 
TABLE 24. Numbers of Rana signata seen at various localities in Sarawak and Sabah (Mendolong only).

\begin{tabular}{|c|c|c|c|c|c|}
\hline & Elevation (m) & Days at site & Number of transects & Stream gradient & Number of $R$. signata \\
\hline \multicolumn{6}{|l|}{ Nanga Tekalit } \\
\hline $1962-1963$ & 150 & 365 & $44^{*}$ & moderate & $94^{*}$ \\
\hline 1970 & & 94 & 20 & moderate & 55 \\
\hline 1984 & & 29 & 17 & moderate & 103 \\
\hline Pesu & $<150$ & 155 & 78 & moderate & 398 \\
\hline Labang & $<100$ & 128 & 29 & low & 27 \\
\hline Segaham & 135 & 61 & 23 & steep & 14 \\
\hline Mendolong & 600 & 25 & 3 & steep & 2 \\
\hline
\end{tabular}

* Excluding observations made during mark-recapture work in 1962-1963.

no more than twice the larval developmental interval. If we assume that the larval period is one to two months long, then the time for a newly transformed juvenile to reach sexual maturity is two to four months. If the estimate of juvenile growth rate is wrong by a factor of two, then the time for a juvenile male to reach sexual maturity is about six to eight months. Unless growth rate among females is much faster, they probably require an additional two to four months to reach sexual maturity. Observation of six males for $>180$ days suggests that survival as an adult for six to 12 months is not rare.

Ecological Distribution--At metamorphosis, juveniles disperse from riparian larval development sites into the forest. Seven of eight in the size range 17.2 to 22.9 SVL were found in forest distant from likely tadpole sites. Two for which we have details of distance and elevation were 40 to $50 \mathrm{~m}$ from the nearest stream and 30 to $50 \mathrm{~m}$ higher than the stream. Of the nine in the size range 28.0 to $34.4 \mathrm{~mm}$, six were in forest distant from streams and three on stream banks. Of the eight subadults in the range 36.0 to $41.4 \mathrm{~mm}$, three were distant from water and five on stream banks. Apparently young juveniles feed in the forest and when nearing sexual maturity return to stream banks and remain there the rest of their lives. It is not known if they return to natal streams; given the occurrence of juveniles near the tops of ridges in hilly country, they may simply move down slope to the nearest stream.

Omitting data from the mark-recapture work at Nanga Tekalit, Sarawak, we have observations on 693 adults. All but 12 were observed $<10 \mathrm{~m}$ from water's edge on perennial streams in primary or slightly disturbed lowland rain forest. With the addition of the 473 observations of $R$. signata during the mark-recapture work, 93\% of 1166 observations were made on streams 8 to $15 \mathrm{~m}$ wide. The majority (55\%) of frogs we saw were less than $1 \mathrm{~m}$ from the water, often on a vertical bank just below a protruding rock or clod of soil. Of those 216 for which we have both horizontal and vertical position data, the most common substrate was soil (43\%), and only $14 \%$ were perched on vegetation, mainly low herbaceous plants.

VARIATION IN NUMBERS-Although $R$. signata was a relatively common species, numbers seen varied greatly from time to time on a given stream, from stream to stream, and from place to place (Table 24). At Nanga Tekalit, where mark-recapture work was carried out for a full year (1962-1963), numbers of $R$.

TABLE 25. Numbers of Rana signata seen per night on three experimental streams at Nanga Tekalit, Sarwak, during three sampling periods.

\begin{tabular}{|c|c|c|c|c|c|c|c|c|c|}
\hline & \multicolumn{3}{|c|}{$1962-1963$} & \multicolumn{3}{|c|}{1970} & \multicolumn{3}{|c|}{1984} \\
\hline & Serbong & Ensurai & Sekentut & Serbong & Ensurai & Sekentut & Serbong & Ensurai & Sekentut \\
\hline \multicolumn{10}{|c|}{ Number of nights } \\
\hline & 3 & 13 & 6 & & 3 & 1 & & 3 & \\
\hline 1 & 1 & 7 & 7 & & 2 & & & 1 & \\
\hline 2 & 2 & 7 & 7 & 1 & & 1 & 1 & & \\
\hline 3 & 2 & 4 & 7 & & 1 & 2 & & 1 & \\
\hline 4 & 2 & 2 & 3 & 3 & & 1 & & & 1 \\
\hline 5 & 3 & 1 & 4 & 1 & & & & & 1 \\
\hline 6 & 3 & 2 & 2 & & & & & & \\
\hline 7 & 1 & & & & & & 1 & & 1 \\
\hline 8 & 3 & & & 1 & & & & & \\
\hline 9 & 6 & & & & & 1 & & & \\
\hline 10 & 1 & & & & & & 1 & & \\
\hline 12 & 1 & & & & & & 1 & & \\
\hline 13 & & & & & & & 1 & & \\
\hline 14 & 1 & & & & & & & & \\
\hline 16 & 2 & & & & & & & & \\
\hline 17 & 1 & & & & & & & & 1 \\
\hline $\begin{array}{l}23 \\
24\end{array}$ & & & & & & & & & 1 \\
\hline $\begin{array}{l}24 \\
25\end{array}$ & $\begin{array}{l}1 \\
3\end{array}$ & & & & & & & & \\
\hline Number of nights & 36 & 36 & 36 & 6 & 6 & 6 & 5 & 5 & 5 \\
\hline Number of observations & 321 & 58 & 86 & & & & & & \\
\hline Total number of individuals & 167 & 40 & 59 & 27 & 5 & 21 & 44 & 4 & 56 \\
\hline
\end{tabular}

* Observations per night. 


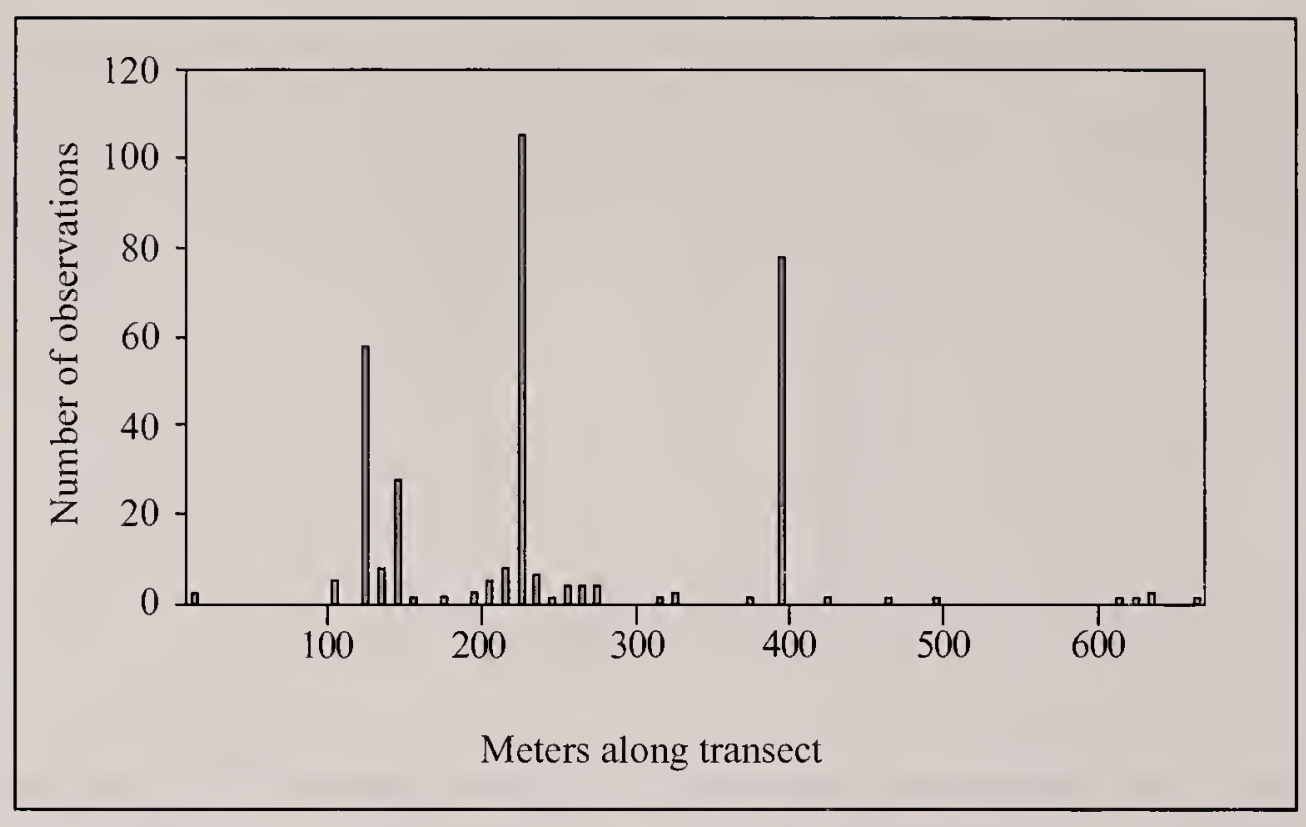

FIG. 12. Spatial distributions of observations of Rana signata on Sungai Serbong, Nanga Tekalit, Sarawak.

signata observed per night varied from zero to 25 (Table 25) in transects measuring 613 to $660 \mathrm{~m}$. On Sungai Serbong, where most $R$. signata were seen that year, numbers observed per night were not dependent on amount of rain on the day of observation ( $r=-0.06, P=0.60)$, on amount on day of observation plus that of the preceding day $(r=-0.15, P=0.18)$, or on amount on day of observation plus that of the two preceding days $(r=$ $-0.18, P=0.13)$. However, the nights of high observation counts were not distributed at random. The five nights with the highest counts of observations fell in the 85-day interval of 3 April to 27 June 1963, when rainfall was $1151 \mathrm{~mm}$ (21\% of total for the year) and observations of $R$. signata totaled 151 (46\% of total for the year). In the two prior 85-day intervals, rainfall was $26.7 \%$ and $39.5 \%$ of the total and observations of $R$. signata $15.7 \%$ and $15.9 \%$ of total, respectively.

Although many more individuals were seen on Sungai Serbong than on the other two streams at Nanga Tekalit in 1962-1963, that was not the case in 1984 (Table 25). Variation in numbers per transect from locality to locality appears to be related to topographic relief (Table 24), although there are not enough data points for statistical confidence.

Spacing AND Movements of Individuals - All the data on these topics are derived from the mark-recapture study at Nanga Tekalit in 1962-1963. Rana signata formed three very distinct clusters on Sungai Serbong (Inger, 1969) (Fig. 12); $69 \%$ of all observations were made in these sites. The clusters were confined to narrower areas than indicated in Figure 12; for example, of the 52 observations made at 112 to $119 \mathrm{~m}, 34$ were at $118 \mathrm{~m}$; of the 98 observations made at 214 to $223 \mathrm{~m}$, 35 were at $217 \mathrm{~m}$ and 35 at $219 \mathrm{~m} ; 62$ of 77 observations in the
381- to 386-m span were made at $382 \mathrm{~m}$. Many of those observations were of individuals seen more than once: the observations at 112 to $119 \mathrm{~m}$ were accounted for by only 33 individuals, the observations at 214 to $223 \mathrm{~m}$ by 53 individuals, and the observations at 381 to $386 \mathrm{~m}$ by only 36 individuals. These cluster sites dominate the pattern of linear movements of this species, as will be seen. On Sungai Sekentut, half the observations were made at four narrow zones $<9$ m wide: 9 at 141 to $147 \mathrm{~m}, 10$ at 202 to $210 \mathrm{~m}, 16$ (of six individuals) at 403 to $405 \mathrm{~m}$, and 9 at 534 to $541 \mathrm{~m}$.

The recapture rate for males was much greater than that for females (Table 26), providing much more information on movements of individuals. Because we do not know where individual frogs were between observations, estimates of amount of movement between observations must be underestimates. The distance moved between successive captures for males on Sungai Serbong ranged from 0 to $493 \mathrm{~m}(n=149)$, with 48 (32\%) showing no movement and 95 (64\%) movements of $<2 \mathrm{~m}$. The interval between captures had a small but significant effect on the distance moved (regression coefficient $=+0.31, P=0.009, n=149$ ). However, these frogs were capable of moving long distances in a short period. Two moved $105 \mathrm{~m}$ in 15 to 19 days, both accomplishing moves between cluster sites. Of the 20 males captured more than three times on Sungai Serbong (accounting for 99 of 286 total observations of males; Table 26), only two were seen outside a cluster area, each only once. Remarkably, a male captured 11 times (Table 26) over a 307-day interval was always found within a 4-m strip at the aggregation site located at 381 to $386 \mathrm{~m}$ (Fig. 12). Of the nine longest movements recorded (82-

TABLE 26. Capture rates of marked individuals of Rana signata on three streams at Nanga Tekalit, Sarawak, in $1962-1963$.

\begin{tabular}{|c|c|c|c|c|c|c|}
\hline & \multicolumn{3}{|c|}{ Males } & \multicolumn{3}{|c|}{ Females } \\
\hline & Serbong & Ensurai & Sekentut & Serbong & Ensurai & Sekentut \\
\hline \multicolumn{7}{|c|}{ Number of individuals } \\
\hline 1 & 65 & 19 & 22 & 27 & 9 & 18 \\
\hline 2 & 34 & 6 & 9 & 2 & 2 & 4 \\
\hline 3 & 18 & 2 & 4 & & 1 & 1 \\
\hline 4 & 10 & & & 1 & & \\
\hline 5 & 6 & 1 & 1 & & & \\
\hline 6 & 3 & & & & & \\
\hline 11 & 1 & & & & & \\
\hline Individuals & 137 & 28 & 36 & 30 & 12 & 23 \\
\hline
\end{tabular}


$493 \mathrm{~m}$ ) for males, five involved movements between cluster sites, one away from a cluster to an "inactive" site (only six observations within a $10-\mathrm{m}$ span), two from inactive sites to a cluster site, and one between inactive sites.

REPRODUCTIVE BEHAVIOR-The clusters of frogs mentioned above consisted mainly of males (see below). In fact, $75 \%$ of the individuals of $R$. signata seen on these streams in 1962-1963 were males. Males were seen and heard calling on almost every night of work along streams, indicating continuous potential breeding. Wide variation in activity levels, measured by numbers of frogs seen, may reflect three kinds of patterns: stochastic, seasonal, or explosive. The occurrence of a few nights with very high numbers of frogs seen on Sungai Serbong in an interval of 85 days (see above) suggests that breeding activity has some seasonal aspects. As noted above, that period was one of reduced rainfall. However, the regression of numbers observed on rainfall is low and not statistically significant (see above). A sufficiently high rainfall ( $>50 \mathrm{~mm}$ ) can cause small streams, like Sungai Serbong, to flood the bars that protect the side pools in which $R$. signata breeds and to flood the usual calling sites along low, steep mud banks.

If a large number of calling males on a given night stimulated females into breeding activity (see Bogert, 1960, e.g., in $B u f o$ ), the number of females observed on such nights should have been higher than on other nights, and females should have been drawn to the cluster sites. Neither of these effects was evident. On the 10 nights with numbers seen $>10$, 23 of the 179 frogs were females; on the other 26 nights, 16 of 148 frogs were females. The difference between the percentages of females on the two groups of nights is not significant $(t=0.55, P>0.20$, arcsin test). Females did not show strong tendency to be drawn to the three cluster sites of males; 16 females were observed at cluster sites and 23 at other points along the stream. In fact, the proportion of males seen at cluster sites (73\% of 288 observations) is much greater than that of females (41\% of 39) ( $t=3.8, P<0.01$, arcsin test).

\section{Rana megalonesa Inger, Stuart \& Iskandar (Fig. 13)}

Rana megalonesa is a green, moderately slender frog with expanded digit tips, long slender legs, conspicuous tympanum, and a white lip. It is primarily an arboreal, lowland rain forest species that also occurs within secondary forest. Adults form breeding aggregations at quiet reaches of streams, though they sometimes breed at ponds. Tadpoles have been found mainly in side pools of streams. At metamorphosis, the juveniles move into the forest to complete growth and development. Adults return to breeding sites at irregular intervals. Until recently,

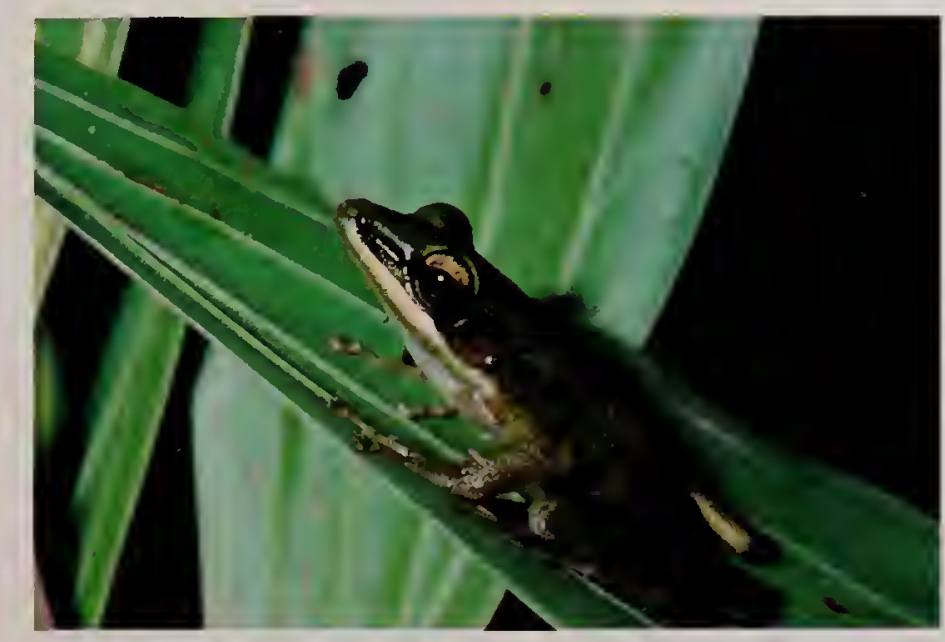

Fig. 13. Rana megalonesa Inger, Stuart \& Iskandar.
TABLE 27. Number of samples of larval Rana megalonesa in various microhabitats in Borneo.

\begin{tabular}{lrllll}
\hline Permanent stream & \multicolumn{2}{c}{$\begin{array}{c}\text { Intermittent } \\
\text { stream }\end{array}$} & \multicolumn{2}{c}{$\begin{array}{c}\text { Nonriparian } \\
\text { sites }\end{array}$} \\
\hline Riffle & 1 & Pool & 18 & Rain pool & 3 \\
Open pool & 8 & & & Permanent pond & 2 \\
Pothole & 11 & & & & \\
Side pool & 43 & & & & \\
\hline
\end{tabular}

these Bornean frogs were confused with Rana chalconota and $R$. raniceps (Inger et al., 2009).

Distr1bution-We observed this species at 14 localities in Brunei, Sabah, and Sarawak from $1^{\circ} 38^{\prime} \mathrm{N}, 113^{\circ} 34^{\prime} \mathrm{E}$ to $6^{\circ} 18^{\prime} \mathrm{N}, 116^{\circ} 43^{\prime} \mathrm{E}$ to $4^{\circ} 25^{\prime} \mathrm{N}, 117^{\circ} 54^{\prime} \mathrm{E}$. At these sites elevations varied from 30 to $750 \mathrm{~m}$ ASL, vegetation types varied from primary lowland rain forest to logged forest, and topography ranged from flat swampy to steep hilly. The various records of $R$. chalconota from Kalimantan (e.g., Veith et al., 2004) may represent $R$. megalonesa.

The Aquatic Phase-Tadpoles develop in a variety of microhabitats (Table 27), although the bulk of our samples were from portions of permanent streams. Only nine $(10 \%)$ of the samples were found in microhabitats having appreciable current, such as riffles and open pools, in contrast to the percentage $(28 \%)$ of all larval samples from these two microhabitats (total samples $=1966$ ). Temperatures in pools occupied by larval $R$. megalonesa measured $21.8^{\circ} \mathrm{C}$ to $28.3^{\circ} \mathrm{C}$ ( $n$ $=19$, median $=22.6^{\circ} \mathrm{C}$ ), oxygen tension varied from $8.0 \%$ to $86.6 \%$ of saturation $(n=19$, median $=43.4 \%$ ), and $\mathrm{pH}$ varied from 4.0 to 6.63 . A single microhabitat could contain a wide range of developmental stages. For example, a side pool (station T360), cut off from the main current of Sungai Purulon, contained 69 tadpoles of $R$. megalonesa in stages 25 to 42 ; it is not clear if one or more clutches were represented in that sample. Head-body length at stage 25 varies from 4.2 to $10 \mathrm{~mm}$, gradually increases to about 13.1 to $15.5 \mathrm{~mm}$ at stage 37 , and levels off beyond that point (Fig. 14). A general description of this larval form is given in Inger (1985, pp. 53-54).

Larvae of $R$. megalonesa are bottom feeders and ingest a variety of small bits of organic matter with no indication of selectivity. Identifiable food particles in foreguts of tadpoles include algae (principally blue-green), diatoms, fungi, miscellaneous protists, and tracheoid plant fragments that range in size from 0.03 to $0.4 \mathrm{~mm}$ (Inger, 1986).

The Terrestr1al Phase-Juveniles with vestiges of tail remaining were 19.3 to $20.8 \mathrm{~mm}$ SVL $(n=3)$. Adult males with nuptial pads and enlarged tympana (and therefore

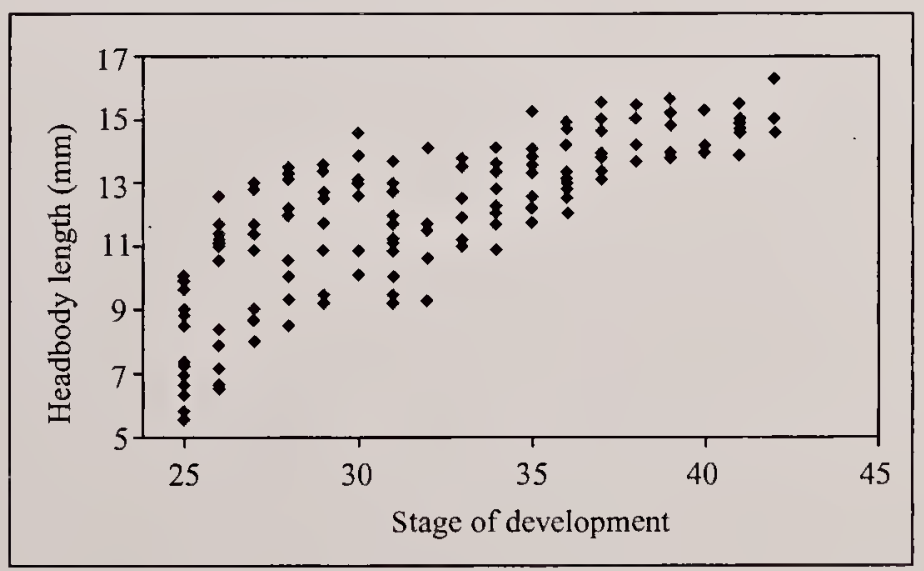

Fig. 14. Stage-size relationship of larval Rana megalonesa. 
TABLE 28. Comparison of vertical positions of adult Rana megalonesa at aquatic and nonaquatic sites.

\begin{tabular}{|c|c|c|c|c|c|c|}
\hline \multirow[b]{3}{*}{ Vertical position } & \multirow{2}{*}{\multicolumn{2}{|c|}{ Nonaquatic }} & \multicolumn{4}{|c|}{ Aquatic sites } \\
\hline & & & \multicolumn{2}{|c|}{ Streams } & \multicolumn{2}{|c|}{ Ponds etc.* } \\
\hline & $n$ & $\%$ & $n$ & $\%$ & $n$ & $\%$ \\
\hline In water & & & 11 & 1.4 & 11 & 16.9 \\
\hline $\begin{array}{l}\text { At/on surface } \\
\text { On vegetation' }\end{array}$ & 15 & 10.5 & 298 & 37.8 & 7 & 10.8 \\
\hline $0-1 \mathrm{~m}$ & 63 & 44.0 & 338 & 42.8 & 45 & 69.2 \\
\hline$>1 \mathrm{~m}$ & 65 & 45.5 & 142 & 18.0 & 2 & 3.1 \\
\hline
\end{tabular}

* Category includes permanent and temporary ponds and swamps.

$\uparrow$ Categories are heights aboveground or above surface of water.

sexually mature) measured 33.3 to $48.2 \mathrm{~mm}$ (mean $\pm \mathrm{SE}=$ $39.21 \pm 0.34, n=113)$. Adult females with convoluted, enlarged oviducts measured 45.4 to $65.6 \mathrm{~mm}$ (mean $\pm \mathrm{SE}=$ $53.66 \pm 0.45, n=115$ ).

Ecological Distribution-At metamorphosis, juveniles disperse from developmental sites. Twelve of 19 in the 19- to $30-\mathrm{mm}$ size range were caught in forest distant from likely natal sites. Larger $(31.3-44.5 \mathrm{~mm})$ but still immature frogs were seen more often (22 of 29) along stream banks. Adult $R$. megalonesa were observed rarely (143 of 1669 observations) away from aquatic sites, yet low recapture rates of marked individuals (see below) suggest that they spend much of their lives in nonriparian situations; this is in marked contrast to observations on the comparably sized $R$. signata, in which the recapture rate was $39 \%$ of 269 marked individuals.

Relatively few frogs were taken at nonaquatic sites (Table 28). Of the 60 frogs observed in forest away from breeding sites, $85 \%$ were perched on vegetation. Only $2 \%$ were seen above $3 \mathrm{~m}$ aboveground. One frog was seen at $4.5 \mathrm{~m}$, one at $9.2 \mathrm{~m}$, and all others below $3.1 \mathrm{~m}$. The vertical distribution of arboreal observations probably reflects the difficulty of spotting frogs in high perches when they are not calling. At aquatic sites, the majority of frogs were also perched in vegetation, but the preponderance of those had low perches, and along streams there was also an increase in the percentage using perches at the ground level (Table 28). The use of lower perches at aquatic sites is probably related to the requirements of oviposition.

DIET-Fourteen frogs with relatively intact prey contained 23 arthropods, with lepidopteran larvae (six) the most numerous and beetles (five) making up the next most abundant food type. Prey size varied from 2 to $27 \mathrm{~mm}$, with small prey $(\leq 5 \mathrm{~mm})$ the most numerous.

VARIATION in Numbers-Numbers of observations in nonriparian situations were too small to permit analysis of

TABle 29. Numbers of Rana megalonesa observed per nocturnal stream transect at six Borneo localities. Data from "Nanga Tekalit 1962" are based on mark-release procedures. All other data are from capture and removal work.

\begin{tabular}{|c|c|c|c|c|c|c|c|c|}
\hline \multirow[b]{2}{*}{ Number per night } & \multicolumn{3}{|c|}{ Nanga Tekalit } & \multirow[b]{2}{*}{ Segaham } & \multirow[b]{2}{*}{ Danum } & \multirow[b]{2}{*}{ Mendolong } & \multirow[b]{2}{*}{ Marak Parak } & \multirow[b]{2}{*}{ Pesu } \\
\hline & 1962 & 1970 & 1984 & & & & & \\
\hline 0 & 36 & & & 9 & 1 & 15 & 6 & 41 \\
\hline 1 & 25 & 4 & 2 & 9 & 15 & 2 & 1 & 10 \\
\hline 2 & 16 & 4 & & 2 & 14 & 2 & 1 & 11 \\
\hline 3 & 10 & 4 & 3 & 1 & 11 & 1 & 1 & 7 \\
\hline 4 & 5 & 3 & 1 & & 5 & 1 & 1 & 4 \\
\hline 5 & 2 & 1 & 1 & 1 & 3 & 3 & & 3 \\
\hline 6 & 3 & & 2 & & 3 & 1 & & 2 \\
\hline 7 & 2 & 1 & & 1 & 3 & 2 & & 1 \\
\hline 8 & 3 & 1 & 1 & 1 & & & & \\
\hline 9 & & & & & 2 & 1 & & \\
\hline 10 & & 1 & & & & & & \\
\hline 11 & & 1 & & & 1 & & & \\
\hline $\begin{array}{l}12 \\
13\end{array}$ & 3 & 1 & & & 1 & 1 & & \\
\hline 15 & & & & & & 1 & & \\
\hline 16 & 1 & & & & & 1 & & \\
\hline 17 & 1 & 1 & & & & & & \\
\hline $\begin{array}{l}19 \\
21\end{array}$ & 1 & & & 1 & & & & \\
\hline 22 & 1 & & 1 & 1 & & & & \\
\hline 24 & & & 1 & & & & & \\
\hline 25 & & 1 & & & & & & \\
\hline 26 & & 1 & 1 & & & & & \\
\hline 37 & & 1 & & & & & & \\
\hline 39 & & & & 1 & & & & \\
\hline Total nights & 109 & 25 & & 26 & 58 & 32 & & 79 \\
\hline Mean & 2.6 & 7.8 & 10.3 & 3.7 & 3.2 & 3.5 & 1.0 & 1.3 \\
\hline
\end{tabular}


TABLE 30. Numbers of Rana megalonesa observed around nights* of high activity at Nanga Tekalit, Sarawak.

\begin{tabular}{llr}
\hline Date & Stream & $\boldsymbol{n}$ \\
\hline 23 Jun 1962 & Sekentut & 6 \\
24 Oct 1962 & Sekentut & 17 \\
25 Oct 1963 & Sekentut & 2 \\
7 Nov 1962 & Serbong & 3 \\
8 Nov 1962 & Serbong & 13 \\
9 Nov 1962 & Serbong & 5 \\
4 Dec 1962 & Sekentut & 13 \\
6 Dec 1962 & Ensurai & 0 \\
7 Dec 1962 & Serbong & 4 \\
13 Mar 1963 & Sekentut & 3 \\
14 Mar 1963 & Ensurai & 22 \\
15 Mar 1963 & Serbong & 19 \\
26 May 1963 & Sekentut & 6 \\
27 May 1963 & Ensurai & 13 \\
28 May 1963 & Serbong & 16 \\
\hline
\end{tabular}

* Manpower resources and requirements of other projects prevented work on more than one stream per night and sometimes limited work to different streams on successive nights.

variation over time or from place to place. Numbers of $R$. megalonesa observed on stream banks during night transects varied greatly over time and from place to place (Table 29). At all localities, the number observed per night on stream transects was usually 0 or 1 and only rarely $>10$.

At Nanga Tekalit, where the most intensive sampling was carried out and for the longest continuous interval (12 months, 1962-1963), there was only weak evidence that nights of high activity were clumped in time, either on a single stream or across streams (Table 30). Nights of high activity (observations per night $>10$ ) were spread through six months of the year, from October through May, during which interval rainfall per month ranged from 235 to $931 \mathrm{~mm}$. Rainfall per month for June and September (data for July and August lost) was 203 and $286 \mathrm{~mm}$. The regression of numbers observed per night to rainfall on the day of observation, to rainfall on the day of observation plus the preceding day, or to rainfall on the day of observation plus the two preceding days was not significant; regression coefficients were, respectively, $-0.036,-0.027$, and 0.016 (associated $P_{\mathrm{S}}>0.07$ ). Rainfall during a week preceding a night of observation of $>10$ individuals varied from 37.5 to $235.1 \mathrm{~mm}$ (mean $=176.0 \mathrm{~mm}, n=7$ ), but only one of those weeks had less than $162 \mathrm{~mm}$. That suggests a period of moderate to heavy rain may have stimulated activity. Nights during which no $R$. megalonesa were seen ( $n$ $=36$ ) were preceded by weeks in which rainfall varied from 6.6 to $286.7 \mathrm{~mm}$ (mean $=116.8 \mathrm{~mm}, n=15$ ), eliminating cases in which dates overlapped. Differences between the two means of rainfall were not statistically significant $(t=1.81$, $P=0.09$ ). Thus, the influence of rainfall on activity is not clear.

Spacing And Movements of Individuals-At Nanga Tekalit, where positions of individual $R$. megalonesa along marked lengths of three streams were recorded during two years, frogs were clearly clustered. In 1962-1963, when transect lengths were 607 to $660 \mathrm{~m}, 26 \%$ to $33 \%$ of all observations of this species were made within one 10 -m strip (approximately 2\% of transect length) on each stream. Observations within three $10-\mathrm{m}$ strips on Sungai Serbong account for $51 \%$ of all observations, and those within two 10 $m$ strips on each of Sungai Ensurai and Sungai Sekentut account for $46 \%$ and $53 \%$, respectively, of all observations on those streams. As few individuals were recaptured (see below), "observations" are essentially equivalent to "individuals." On Sungai Serbong and Sungai Sekentut, the hot spots were located adjacent to side pools, the common microhabitat of tadpoles of this species. On nights in which many $(>10)$ individuals were seen, large proportions of those frogs were seen at hot spots: $75 \%$ on Sungai Serbong, $77 \%$ on Sungai Ensurai, and $60 \%$ on Sungai Sekentut.

In 1970, when all frogs were removed as captured, during five transects on each of those same streams over a 94-day interval, $21 \%$ of individuals on Sungai Serbong were seen within a $10-\mathrm{m}$ strip, and $32 \%$ were seen within a $10-\mathrm{m}$ strip on Sungai Ensurai. There was no comparable concentration on Sungai Sekentut.

Information on movements comes from recapture of 30 frogs (of 252 marked) at Nanga Tekalit, only three of which were captured more than twice. Males, especially, showed high fidelity to locations on stream banks. Of the 22 marked males recaptured, 13 were within $10 \mathrm{~m}$ of the previous point of capture; eight had moved $<5 \mathrm{~m}$ over periods $>55$ days. However, males are capable of large shifts in position, with three moving 209 to $298 \mathrm{~m}$ from their original positions in 29 to 99 days. Females tended to move more than males, with only two of eight moving less than $10 \mathrm{~m}$; one female moved $243 \mathrm{~m}$ in 18 days. Neither sex showed any relationship between interval in days and distance moved between successive captures. The small number of recaptures along these streams, only $12 \%$, is strong evidence that adults spend much of their time away from breeding sites.

REPRODUCTIVE BEHAVIOR-Rana megalonesa breeds along small to medium-sized streams, small intermittent streams, and, less often, at ponds in forests, with males forming aggregations. The concentrations of individuals along the experimental streams at Nanga Tekalit (see above) consisted mainly of calling males, with females accounting for $17 \%$ and $20 \%$ of 35 and 25 observations, respectively, at two sites but much less than that at other sites. On five of the seven nights with observation $>10$, the number of females observed was three; in these seven nights, females accounted for 10 of 76 observations at the sites of aggregations.

Breeding takes place throughout the year, with activity only weakly related to amount of monthly rainfall. All males with SVL $>35 \mathrm{~mm}$ collected throughout the year had welldeveloped secondary sex characters: enlarged tympanum and well-developed nuptial pads. Gravid females were observed every month except November at Nanga Tekalit during the 12-month period from September 1962 to September 1963. The percentage of gravid females among those preserved and dissected was highest from December through April $(62 \%-$ $90 \%$ ), among months in which number of mature females dissected $>7$, and lowest in May (22\%) and June (31\%). As noted above, nights of high activity on experimental streams at Nanga Tekalit occurred in October through May. February and May were months of high rainfall (931 and $725 \mathrm{~mm}$, respectively) and April and June months of relatively low rainfall (236 and $203 \mathrm{~mm}$, respectively). Clutch size determined from dissected females varied from 710 to 1387 (mean $\pm \mathrm{SE}=1104 \pm 64.8, n=10)$. 
TABLE 31. Numbers and directions of long moves $(>100 \mathrm{~m})$ between successive captures and of long net distances for marked individuals of five species of Bornean frogs at Nanga Tekalit, Sarawak.

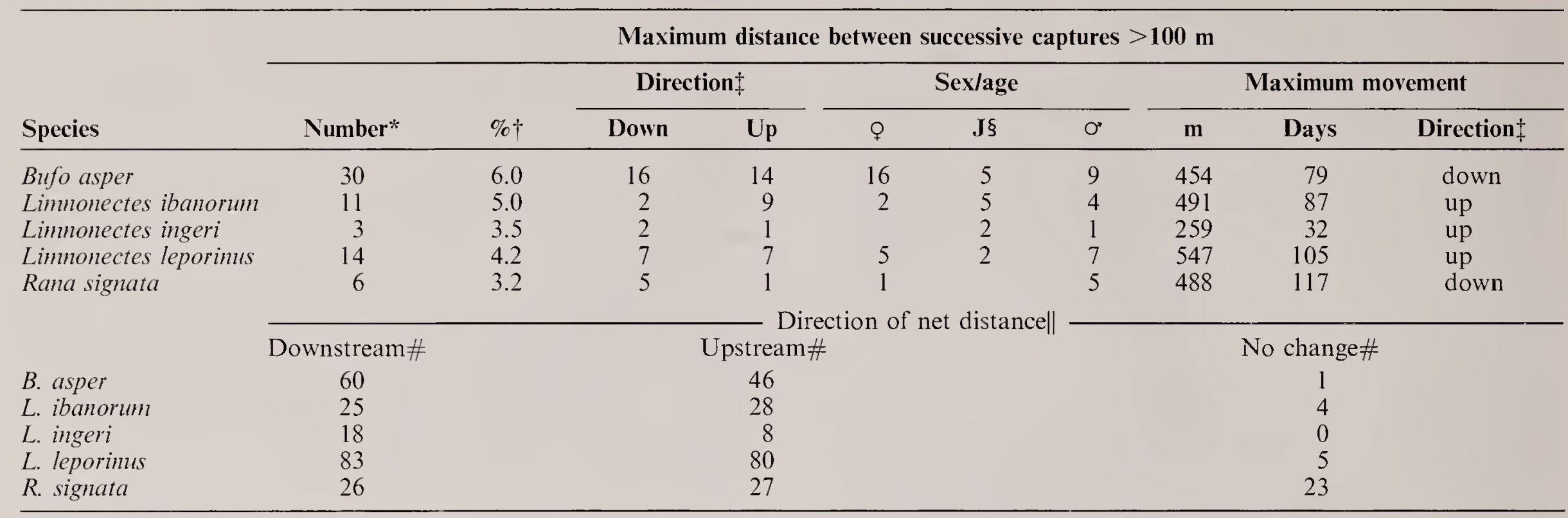

* Number of movements, not individuals.

$\uparrow$ Percentage of recaptures within species.

$\ddagger$ Down = downstream; up $=$ upstream.

$\S \mathrm{J}=$ juveniles.

|l Distance between first and last capture.

\# Number of individuals.

\section{Discussion}

Marked individuals of five species were recaptured frequently at Nanga Tekalit. A few of those individuals moved relatively great distances $(\geq 100 \mathrm{~m}$, about 1000 times the body lengths of the larger frogs) between successive capture points (Table 31). Adults, males and females, as well as juveniles made these occasional long moves. In all five species, males made more long moves than females. The greatest disparity between the sexes occurred in $R$. signata, in which five of the six long moves were made by males; however, only $17 \%$ of marked females of $R$. signata were recaptured compared to $47 \%$ of marked males, making the preponderance of males in the long-move category expected. A large proportion of long moves were made by juveniles only in L. ibanorum (five of 11 ).

Very few or no individuals of these five species were found away from stream banks. For example, only five $B$. asper (of 870 individuals) were found away from stream banks, and of those, three were in a swamp forest where most of the surface was covered with water. No $L$. ibanorum and no $L$. leporinus were found away from stream banks. Only $16 R$. signata (of 693) were found away from stream banks, and the bulk of those 16 were juveniles and subadults. Limnonectes ingeri, of this group of species, is the one most likely to move away from stream banks, although none were found in nonriparian situations at Nanga Tekalit. Given the strong riparian habits of these five species, it is appropriate to assume that these long movements were made along the length of the stream. As downstream movements could have been assisted strongly by current, the upstream movements are the ones that give measures of the potential dispersal capacities of these species. Bufo asper clearly accounts for most of the long-distance moves. It is also the only species in which some individuals made these long moves more than once. For example, frog 14 was captured on 18 nights (of 36) and moved more than $100 \mathrm{~m}$ during five intervals between successive captures, three moves upstream and two downstream. This pattern is in sharp contrast to that of another B. asper, frog 202, which was captured 30 times; the maximum distance between successive capture points for this individual was $19.2 \mathrm{~m}$.

The stimulus for these long movements is unknown, but one of their effects is likely to be the swamping of any local genetic differentiation by distance, especially for species, such as $B$. asper and $L$. leporinus, that occur along very large as well as medium-sized streams. The capacity for long-distance dispersal may help explain the wide geographic range of species, such as B. asper and R. signata, that occur from southern Thailand through most of the Greater Sundas. However, the directions of these movements and of net distance (Table 31) give no clear indication of sustained upstream or downstream movement of these species.

Although all seven of the species dealt with in this paper breed at streams, one of them (L. kuhlii) is found relatively often at nonriparian habitats such as ponds, and another ( $R$. megalonesa) is presumed to carry out nonreproductive activity in nonriparian parts of forest. Juveniles of a third species $(R$. signata) complete their growth far from stream banks, and adults of another species ( $L$. ingeri) move through flat areas of forest away from stream banks. They differ significantly in the types of lowland woodlands they inhabit (Table 32). All have

TABLE 32. Types of forest occupied by seven riparian-breeding Bornean frogs.

\begin{tabular}{|c|c|c|c|c|c|}
\hline & \multirow[b]{2}{*}{ Swamp } & \multicolumn{2}{|c|}{ Primary } & \multirow[b]{2}{*}{ Secondary } & \multirow{2}{*}{$\begin{array}{c}\text { Acacia } \\
\text { plantation }\end{array}$} \\
\hline & & Flat & Hilly & & \\
\hline Bufo asper & + & + & + & + & \\
\hline Limnonectes ibanorum & & & + & + & \\
\hline Limnonectes ingeri & + & + & + & + & + \\
\hline Limnonectes kuhlii & & & + & + & \\
\hline Linnonectes leporinus & & + & + & + & + \\
\hline Rana megalonesa & + & + & + & + & + \\
\hline Rana signata & & + & + & + & + \\
\hline
\end{tabular}


been found in hilly primary and secondary rain forest. Limnonectes ingeri and $R$. megalonesa have been found in the most types of forest: swamp forest, flat as well as hilly primary forest, secondary forest, and Acacia plantations. Limnonectes ibanorum and $L$. kuhlii appear to be the most restricted. Only $L$. kuhlii occurs in montane as well as lowland forest. Just one species, L. ibanorum, seems to have a geographically restricted distribution within Borneo, never having been observed in the state of Sabah (Inger \& Stuebing, 2005).

Given their distribution in forest types, this suite of streambreeding frogs should persist despite the shrinkage of the forested area of Borneo as long as large areas of closed-canopy secondary forests exist.

\section{Acknowledgments}

The fieldwork was supported by National Science Foundation grants G 20867, GB 1049, and GB 7845X and by grants from The Marshall Field III Fund of The Field Museum. Permits to do the field research were granted at various times by Sabah Parks and the Forestry Department of Sarawak. Researchers who participated in the fieldwork in various years included J. P. Bacon, K. J. Frogner, W. Hosmer, F. W. King, Leong T.-M., R. B. Stuebing, Tan F.-L., H. K. Voris, and P. Walker. Collection of specimens and data in the field would have been almost impossible without the able assistance of Abas, Aran, Bajok, and Jarau of the Rumah Anyie longhouse and Gaun Sureng, Frederick and Patrick Francis, Danson Kandaung, Freddy Paulus, and Paul Yambun. I am grateful to these persons for help and companionship in the field. I also thank A. Resetar and P. Lowther for important assistance in the laboratory.

\section{Literature Cited}

Airame, S. 1999. Population structure and viability of streamdwelling frogs on Borneo. Doctoral diss., University of Chicago. $218 \mathrm{pp}$.

BOGERT, C. M. 1960. The influence of sound on the behavior of amphibians and reptiles, pp. 137-320. In Animal Sounds and Communication. American Institute of Biological Sciences.

Boulenger, G. A. 1920. A monograph of the South Asian, Papuan, Melanesian and Australian frogs of the genus Rana. Records of the Indian Museum, 20: 1-226.

Caldwell, J. P., J. H. Thorp, and T. O. Jervey. 1980. Predator-prey relationships among larval dragonflies, salamanders, and frogs. Oecologia, 46: 285-289.

DAs, I. 1995. Amphibians and reptiles recorded at Batu Apoi, a lowland forest in Brunei Darussalam. Raffles Bulletin of Zoology, 43: $157-180$.

Dring, J. C. M. 1979. Amphibians and reptiles from northern Trengganu, Malaysia, with descriptions of two new geckos: Cnemaspis and Cyrtodactylus. Bulletin of the British Museum (Natural History) Zoology, 34: 181-241.

Emerson, S. B. 1992. Courtship and nest-building behavior of a Bornean frog, Rana blythii. Copeia, 1992: 1123-1127.
Emerson, S. B., R. F. Inger, And D. Iskandar. 2000. Molecular systematics and biogeography of the fanged frogs of Southeast Asia. Molecular Phylogenetics and Evolution, 16: 131-142.

Gosner, K. L. 1960. A simplified table for staging anuran embryos and larvae with notes on identification. Herpetologica, 116: 183-190.

INGER, R. F. 1956. Some amphibians from the lowlands of North Borneo. Fieldiana: Zoology, 34: 389-424.

. 1966. The systematics and zoogeography of the Amphibia of Borneo. Fieldiana: Zoology, 52: 1-402.

. 1969. Organization of communities of frogs along small rain forest streams in Sarawak. Journal of Animal Ecology, 38: 123-148. 1985. Tadpoles of the forested regions of Borneo. Fieldiana: Zoology, n.s., 26: 1-89.

1986. Diets of tadpoles living in a Bornean rain forest. Alytes, 5: $153-164$

. 1992. A bimodal feeding system in a stream-dwelling larva of Rhacophorus from Borneo. Copeia, 1992: 887-890.

1994. Microhabitat description, pp. 60-66. In W. R. Heyer et al., eds. Measuring and Monitoring Biological Diversity: Standard Methods for Amphibians.

INGER, R. F., AND J. P. BACON, JR. 1968. Annual reproduction and clutch size in rain forest frogs from Sarawak. Copeia, 1968: 602-606.

INGER, R. F., AND B. GREENBERG. 1966. Ecological and competitive relations among three species of frogs (genus Rana). Ecology, 47: 746-759.

INGER, R. F., B. L. STUART, and D. T. Iskandar. 2009. Systematics of a widespread Southeast Asian frog, Rana chalconota (Amphibia: Anura: Ranidae). Zoological Journal of the Linnean Society, 155: 123-147.

Inger, R. F., And R. B. Stuebing. 2005. A Field Guide to the Frogs of Borneo, 2nd ed. Natural History Publications, Kota Kinabalu.

INGER, R. F., AND H. K. Voris. 1986. Larval transport in a Bornean frog. Copeia, 1986: 523-525.

1993. A comparison of amphibian communities through time and from place to place in Bornean forests. Journal of Tropical Ecology, 9: 409-433.

INGER, R. F., H. K. Voris, AND K. J. Frogner. 1986. Organization of a community of tadpoles in rain forest streams in Borneo. Journal of Tropical Ecology, 2: 193-205.

Jolly, G. M. 1965. Explicit estimates from capture-recapture data with both death and immigration-Stochastic model. Biometrika, 52: $225-247$.

LIEM, K. F. 1961. On the taxonomic status and the granular patches of the Javanese frog Rana chalconota Schlegel. Herpetologica, 17: 69-71.

Pope, C. H. 1964. Amphibians and Reptiles of the Chicago Area. Chicago Natural History Museum, Chicago.

Smith, M. A. 1930. The reptilia and amphibia of the Malay Peninsula. Bulletin of the Raffles Museum, 3: 1-149.

Stuart, S., M. Hoffmann, J. S. Chanson, N. A. Cox, R. J. Berridge, P. Ramani, AND B. E. Young. 2008. Threatened Amphibians of the World. Lynx Ediciones, Barcelona, Spain: IUCN, Gland, Switzerland: Conservation International, Arlington, Virginia.

Terentjev, P. V., And S. A. Chernov. 1965. Key to Amphibians and Reptiles, 3rd ed. Moscow. English translation by L. Kochva, Jerusalem.

Veith, M., S. Wulffraat, J. Kosuch, G. Hallmann, H.-W. Henkel, P. Sound, Samsu, L. Rudhimanto, And D. Iskandar. 2004. Amphibians of the Kayan Mentarang National Park (East Kalimantan): Estimating overall and local species richness. Tropical Zoology, 17: 1-13. 



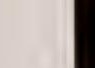



Telephone: (312) 665-7769 